Apidologie, 1975, 6 (3), 233-281.

\title{
BEITRÄGE ZUR KENNTNIS DES PAARUNGSFLUGES DER HONIGBIENE
}

\author{
Contribution à la connaissance du vol nuptial de l'abeille \\ (Apis mellifica L.)
}

Friedrich Karl BÖTTCHER

Bayerische Landesanstalt für Bienenzucht, D 852 Erlangen

\begin{abstract}
SUMMARY
CONTRIB UTIONS TO THE KNOWLEDGE OF THE MATING FLIGHT OF THE HONEYBEE (Apis mellifica mellifica L.)
\end{abstract}

1. In the environs of Erlangen we know seven drone congregation areas : one of them on an unwooded hillrange and six (A-F) above a hilly woodland surrounding our former queenmating station « Hohe Mark ». Five of the six places are situated within a radius of $1500 \mathrm{~m}$. Every year they are visited by drones of the environment.

2. The removal of the $\mathbf{1 0}$ drone colonies from our mating-station did not cause any visible diminution of drones being enticed by experimental queens. So, the drones assembling at these congregation areas mostly are coming from apiaries that are located $2 \mathrm{~km}$ and more away.

3. The congregation areas were frequented by the drones from mid-May until the end of August. In cloudy weather they used to fly lower than in a clear atmosphere. When, after a period of bad weather, the temperatures suddenly increased to high degrees, it could happen that, after initially numerous approaches, the drones failed to appear after the second day.

4. In balloon experiments it was possible to entice drones over colonies abundant in drones, even in places which are not congregation areas. Just as at congregation areas, we succeeded here in bringing drones to copulate with dead queens whose sting chamber had been opened artificially.

5. The cordovan queens located in such areas did not preferably mate with the drones flying there. This results from a comparison of the colour of these drones with the female progeny of those queens. Even if their location was situated at a drone congregation area, the queens generally left it for mating.

6. How far and where the queens had flown to for mating has been tested with mated queens on induced return flights : 
a) The number of returning queens was, on the whole, the higher and the duration of their return flights the shorter, the nearer the departure places at their location were to the congregation area $\mathrm{A}$.

b) In spite of this general tendency, the queens' return from congregation place C, situated, $650 \mathrm{~m}$ north-west and well frequented by drones was inferior to that from congregation area $B$, situated almost at the same distance $(600 \mathrm{~m})$, but in the south-south-west direction, and also from place $D$, situated south-south-east $800 \mathrm{~m}$ away. The number of queens returning from $\mathrm{C}$ was less, and their returning flights took more time.

Consequently, queens at their mating flights preferred the area in southern direction towards the end of the valley.

Possibly they let themselves be guided there by hillranges or horizon marks; or the direction of the wind could have played a role.

c) Three places, about $2000 \mathrm{~m}$ away from their location (the drone congregation area $\mathrm{F}$ and the two neutral areas $Z$ and $Y$ ) were almost unknown to the queens.

d) The region farther away than $1000 \mathrm{~m}$ was unknown to most of the queens. Generally, they did not fly beyond it.

e) It could not be decided if the queens sought for drone congregation areas.

$f$ ) On their forced returns about $14 \%$ of the returning home queens had mated once more.

\section{ZUSAMMENFASSUNG}

1. In der Umgebung von Erlangen kennen wir 7 Drohnensammelplätze : Einen auf einem unbewaldeten Höhenzug und 6 (A-F) über einem hügeligen Waldgebiet um unsere ehemalige Belegstelle “ Hohe Mark ». Allein 5 von diesen 6 befinden sich in einem Kreis von $1500 \mathrm{~m}$ Halbmesser. Sie werden alljährlich von den Drohnen der Umgebung aufgesucht.

2. Abtransport der 10 Drohnenvölker von unserer Belegstelle bewirkte keine sichtliche Verminderung der auf den Sammelplätzen von den Versuchsköniginnen angelockten Drohnen. Somit kommen die Drohnen zu diesen Sammelplätzen zu allermeist von den $2 \mathrm{~km}$ und mehr entfernten Bienenständen.

3. Die Drohnen besuchten die Sammelplätze von Mitte Mai bis Ende August. Bei trüber Atmosphäre flogen sie tiefer als bei klarem Wetter. Wurde es nach einer Schlechtwetterperiode plötzlich sehr heiß, konnten sie nach zunächst sehr gutem Anflug vom zweiten Tag an ausbleiben.

4. Auch an Orten, die keine Drohnensammelplätze sind, ließen sich die Drohnen über drohnenreichen Völkern in Ballonversuchen anlocken. Ebenso wie auf den Drohnensammelplätzen gelang es auch hier, die Drohnen mit toten Königinnen zur Kopulation zu bringen, deren Stachelkammer künstlich aufgespreizt worden war.

5. Die auf solchen Stellen aufgestellten cordovan-Königinnen paarten sich aber nicht vorzugsweise mit den hier fliegenden Drohnen. Das geht aus dem Farbvergleich dieser Drohnen mit der weiblichen Nachkommenschaft der Königinnen hervor. Selbst dann verließen die Königinnen zumeist ihren Standplatz zur Paarung, wenn dieser ein Drohnensammelplatz war.

6. Wie weit und wohin die Königinnen zur Paarung geflogen waren, wurde in Rückfliegeversuchen mit begatteten Königinnen geprüft.

a) Die Zahl der heimkehrenden Königinnen war im ganzen umso größer und die Dauer ihrer Rückflüge umso kürzer, je näher sich die Ab flugstellen beim Standort der Königinnen, dem Drohnensammelplatz $A$, befanden.

b) Trotz dieser allgemeinen Tendenz war die Rückkehr der Königinnen von dem $650 \mathrm{~m}$ nordwestlich gelegenen stark von Drohnen besuchten Sammelplatz C weniger gut als von dem etwa gleich weit $(600 \mathrm{~m})$ aber südsüdwestlich liegenden Sammelplatz B und dem $800 \mathrm{~m}$ südsüdöstlich liegenden Sammelplatz D. Die Zahl der Rückkehrer von C war geringer, und ihre Rück flüge dauerten länger.

Somit bevorzugten die Königinnen bei ihren Paarungsflügen das in südlicher Richtung zum Talausgang hin gelegene Gebiet.

Es ist möglich, daß sie sich durch Höhenzüge oder Horizontmarken hierhin leiten ließen, oder daß die Windrichtung dabei eine Rolle spielte.

c) 3 Plätze in etwa $2000 \mathrm{~m}$ Entfernung von ihrem Standplatz (der Drohnensammelplatz F und die zwei neutralen Stellen $Z$ und $Y$ ) waren den Königinnen so gut wie unbekannt. 
d) Den meisten Königinnen war die Gegend über $1000 \mathrm{~m}$ nicht bekannt. Sie dürftsn im allgemeinen nicht weiter ge flogen sein.

e) Ob die Königinnen zur Paarung die Drohnensammelplätze aufsuchten, ließ sich nicht entscheiden.

f) Ca $14 \%$ der zurückgekehrten Königinnen hatten sich auf dem erzwungenen Rück flug abermals gepaart.

\section{EINLEITUNG}

Die Geschlechtstiere der Honigbiene, die Königinnen und die Drohnen, paaren sich im Fluge, hoch in der Luft. Sehr selten ist dieser Vorgang zu beobachten : Nur wenn er ganz ausnahmsweise einmal in der Nähe der Erdbodens erfolgt. Über den Ort der Paarung haben wir bisher noch keine genaue Kenntnis.

Indirekt, mit Hilfe genetisch markierten Bienenmaterials, ließ sich ermitteln, daß sich die Königinnen und Drohnen bis zu einer Höchstentfernung von $16 \mathrm{~km}$ zusammenfinden können, wenn sie so weit voneinander getrennt stehen (Klat 1929-1932, Peer 1957), und daß Paarungen auf 9-10 km Entfernung selbst dann vorkommen, wenn es nahe bei den Königinnen nicht an Drohnen mangelt (Peer und Farrar 1956).

Von den Drohnen wissen wir, daß sie sich an bestimmten Stellen in einer Höhe von 10-50 m über dem Gelände fliegend versammeln, ohne etwa von Königinnen dorthin gelockt worden zu sein (Doolittle 1892, JeAN-Prost 1958, F. u. H. Rutwner 1965). Sie kommen zu diesen Drohnensammelplätzen aus Entfernungen bis 5, 6 und $7 \mathrm{~km}$.

\section{FRAGESTELLUNG}

Ob auch die Königinnen dorthin fliegen, um sich da zu paaren, ist eine noch offene Frage. Beobachten konnte man das bisher nicht. Auch sonst haben wir keine Beweise dafür. Aber manches spricht dafür : Vor allem, daß sich hier die Drohnen vom Königinnenduft in großer Zahl anlocken lassen, ihm aber über den Drohnensammelplatz hinaus nicht folgen.

Indessen konnten sich ButLer und FAIRey (1964) an der britischen Küste nicht vom Bestehen von Drohnensammelplätzen überzeugen. Bei Wind hatte der Königinnenduft überall im Luftraum über dem dortigen Gelände eine drohnenanlockende Wirkung. H. und F. RutTner (1972) hingegen entdeckten Drohnensammelplätze an der deutschen und dänischen Nordseeküste, dazu in Tunis, bei Wind in nur wenigen Metern Höhe über dem Erdboden.

Im folgenden wird über Drohnensammelplätze in der Umgebung von Erlangen berichtet (A, S. 236) und der Frage der Drohnenanlockung über Bienenständen auf neutralen Plätzen nachgegangen (B, S. 240). Weiter wird 
untersucht, ob die Königinnen vielleicht zur Paarung bei ihrem Standort bleiben, sei dieser nun ein neutraler Platz (C, S. 247) oder ein Drohnensammelplatz (D, S. 253) und falls nicht, wohin und wie weit sie gewöhnlich zur Paarung fliegen (E, S. 261).

\section{A. - DROHNENSAMMELPLÄTZE}

a) Topographie

Im Umkreis von nur $1000 \mathrm{~m}$ um unsere ehemalige Belegstelle « Hohe Mark » (Abb. 1) fanden wir 5 Drohnensammelplätze : Den ersten (E) entdeckten

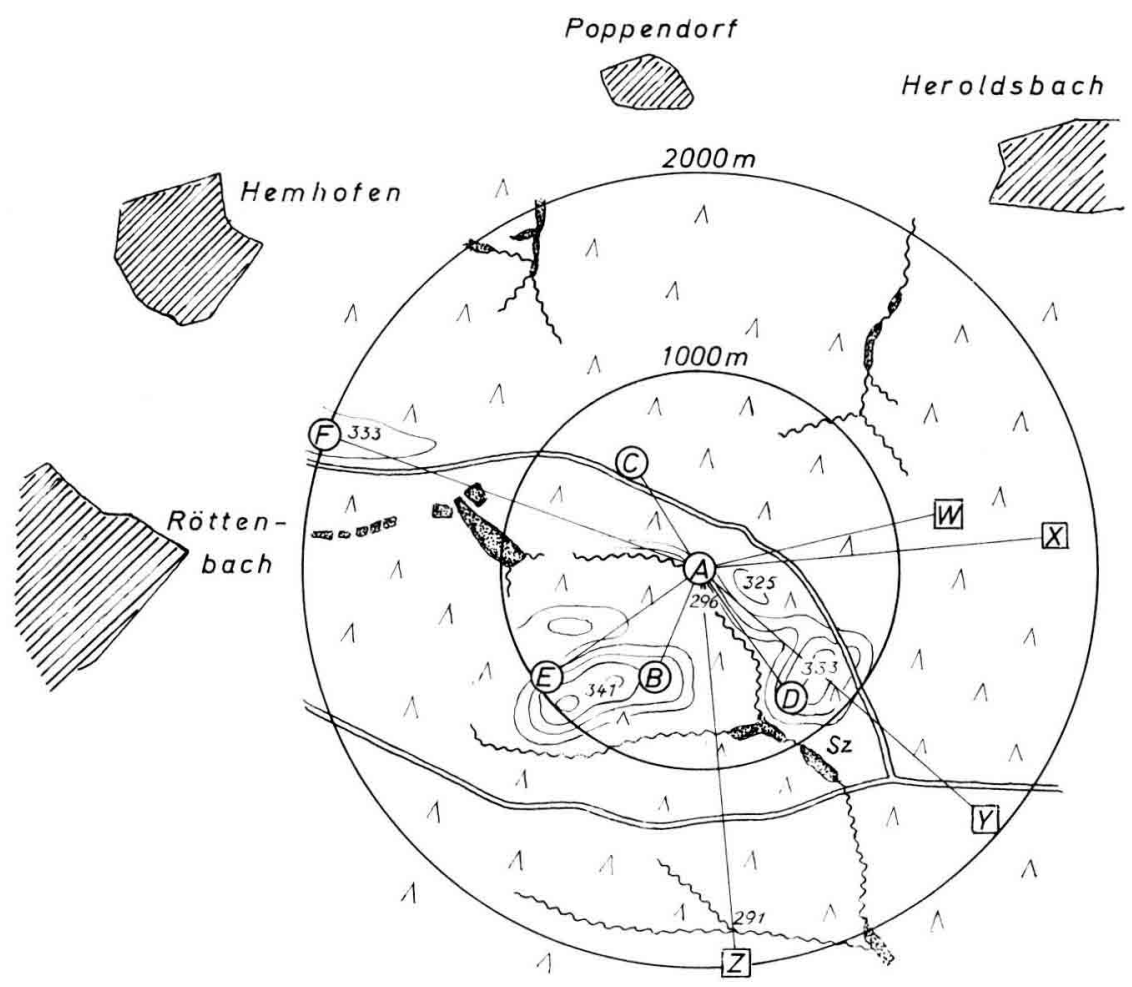

Авв. 1. - Lage der Drohnensammelplätze $A-F$ und der neutralen Versuchsplätze $W-Z . S z=$ Schwarzer Weiher.

Fig. 1. - Situation des lieux de rassemblement de mâles $A$ à $F$ et des lieux d'expérience neutres $W \grave{a} Z . S z=$ Etang noir.

wir sehr schnell. Denn unsere Imkermeister Franz und Riedel erinnerten sich, dort im Jahr zuvor einen Drohnenschwarm gesehen zu haben, der offenbar eine 
Königin verfolgte. Schon der allererste Ballonversuch (nach GARY 1963, jedoch mit gekäfigter Königin) ergab hier ein starkes Anspielen der Lockkönigin durch zahlreiche Drohnen. Die anderen vier Plätze B, D, A und C fanden wir bei systematischer Suche bald darauf. Später entdeckten wir in $2000 \mathrm{~m}$ Entfernung noch einen sechsten (F), und schließlich in einer anderen Gegend, auf einem so gut wie baumlosen Höhenzug beim Wasserturm von Marloffstein noch einen siebenten. Zweifellos ließe sich ihre Zahl bei weiterem Suchen laufend vergrößern.

Zwei der entdeckten Sammelplätze (B und D) liegen auf Bergen, einer (A) liegt in einem Tal über einem Sumpf und über einem es nach Osten begrenzenden stark ansteigenden Hang, und drei liegen in einem mehr ebenen Gelände : Einer (F) an einem leichten Hügel, der zweite (E) über einer flachen Mulde, und der dritte (C) über einem allmählich ansteigenden Gelände. Unmittelbar beim Drohnensammelplatz $B$ befand sich seit langem unsere Belegstelle (c Hohe Mark ) mit etwa 10 Drohnenvölkern.

Die genaue Ausdehnung dieser Sammelplätze wurde nicht festgestellt. Ist doch das ganze Gebiet ein hügeliges Waldgelände mit hohem und ziemlich geschlossenem Föhrenbestand, der eine genaue Untersuchung dieser Art sehr erschwert, wenn sicht unmöglich macht. Indessen ist sicher, daß diese Sammelplätze begrenzt sind. Denn nicht weit davon ließen sich nur noch vereinzelte Drohnen anlocken.

Überlegungen, warum sich gerade an diesen Stellen die Drohnen versammeln, führten zu keinem Ergebnis. Die Plätze $\mathrm{E}$ und $\mathrm{C}$ sind beide z. T. mit einem Gemisch von Föhren und Eichen bestanden. U̇ber einer ganz ähnlich bewachsenen Stelle fanden sich jedoch keine Drohnen. Bei A stehen im Sumpf selbst nur wenige Föhren. Da sich das ganze Gebiet zwischen flachen Tälern aus der Landschaft heraushebt, ist das Bestehen von Richtreizen für die Drohnen im Sinne von F. und H. Rutreer (1968) denkbar.

\section{b) Überprüfung}

Vier Jahre lang, von 1966 bis 1969, und zum Teil auch in späteren Jahren wurden die Drohnensammelplätze geprüft. Stets erwiesen sie sich als mehr oder weniger stark von Drohnen besucht. Bei günstigem windstillen Wetter konnte man das Summen der Drohnen vom Erdboden aus wahrnehmen. Die Überprüfung des Jahres 1968 sei hier geschildert :

Am 18-6-1968, bei etwas trübem windigen Wetter, prüften wir zunächst drei Drohnensammelplätze, darunter auch den kaum $50 \mathrm{~m}$ östlich der Belegstelle Hohe Mark mit ihren 10 Drohnenvölkern gelegenen Platz B. Hier fanden sich 14.15 Uhr bei der Königin im Käfig am Ballon neben einem hohen Föhren- 
überhälter 5-6 Drohnen. (Dieser Platz war im allgemeinen schwach besucht, doch konnten wir oft auch mehr, z. B. am 23-6-1967 etwa 50 Drohnen verzeichnen.) Eine dreiviertel Stunde später stellten sich am Drohnensammelplatz E etwa 50 Drohnen bei der Königin am Ballon ein, und bei C war gegen 16 Uhr ein guter Anflug von etwa einem Dutzend Drohnen festzustellen. Die Drohnen flogen also auf diesen 3 Plätzen wie in den Vorjahren.

Am folgenden Tag, dem 19-6 erhielten wir bei ziemlich windstillem, sehr warmem Wetter $\left(26^{\circ} \mathrm{C}\right)$ und meist sonnigem Himmel von 14.00 bis $14.30 \mathrm{Uhr}$ bei dem Überhälter auf dem Sammelplatz B einen Anflug von etwa einem Dutzend Drohnen.

Bei dem Drohnensammelplatz E zeigte sich an diesem Tag zwischen 14.4014.50 Uhr bei bedecktem Himmel ein sehr starker Drohnenan flug von schätzungsweise bis zu 100 Drohnen.

Im Gebiet von C, wo man ein starkes Summen hörte, flogen etwa 60-70 Drohnen die Königin an.

Auf D mit seinem dichten Hochwaldbestand konnte man das Summen der Drohnen nur schwach vernehmen. 10-15 Drohnen flogen die Königin an.

Bei A hörte man um 15.30 Uhr starkes Summen und konnte etwa 20 Drohnen beim Anflug auf die Königin beobachten.

Es stand damit fest, daß alle 5 Drohnensammelplätze wie in den Vorjahren $(1966,1967)$ von den Drohnen besucht wurden, und in den folgenden Jahren war es nicht anders.

Ergebnis :

Also ist zu bestätigen, daß es Drohnensammelplätze mit alljährlich gleichem Drohnenbesuch gibt.

c) Was bedeuten 10 Drohnenvölker auf einer Belegstelle für den Drohnenbesuch der benachbarten Sammelplätze?

Es war von großem praktischen Interesse zu erfahren, ob die Drohnen der Sammelplätze überwiegend von den 10 Drohnenvölkern der Belegstelle Hohe Mark (Abb. 1 bei B) stammten, oder von den mindestens $2-4 \mathrm{~km}$ entfernten Völkern der Umgebung. Wir transportierten deshalb die Drohnenvölker am 19-6-1968 von der Belegstelle ab.

Als am 23-6 nach einem Wettersturz wieder schönes, warmes Wetter $\left(25^{\circ} \mathrm{C}\right)$ einsetzte, konnte auf den Sammelplätzen E und C um 15 und 16 Uhr starkes Summen wahrgenommen und eine Anlockung von jeweils etwa 40 
Drohnen festgestellt werden. Auf den drei anderen Plätzen, wo nur zwischen 16.30 und 17.30 Uhr geprüft werden konnte, wurde unsere Versuchskönigin nicht mehr von Drohnen ange flogen.

Indessen, bei einer Wiederholung dieser U̇berprüfung am 27-6 zu früherer Tageszeit, wenn auch bei ungünstigerem Wetter, herrschte auf diesen 3 Plätzen gleichfalls guter Drohnenan flug, nämlich auf A um 14.45 Uhr von 20 Drohnen, auf B, also dem Platz neben der Belegstelle selbst um 15 Uhr von etwa 15 Drohnen und auf D von etwa 15 Drohnen, während ein kurzer Vergleichsversuch auf C den Anflug von 10 Drohnen ergeben hatte. Am späten Nachmittag hingegen bis 16.25 Uhr kamen bei A nur noch 6-8, gegen 17 Uhr nur einzelne Drohnen und von 17.25-17.30 Uhr überhaupt keine mehr.

Wenn wir also am 23-6 auf diesen 3 Plätzen keine Drohnen gefunden hatten, so lag das daran, daß die Prüfung bei zu später Tageszeit erfolgt war. Ergebnis :

Mithin ist festzustellen, daß trotz Abtransport unserer 10 Drohnenvölker von der Belegstelle auf allen Sammelplätzen noch Drohnen in großer Zahl flogen, die nur von den 2-4 und mehr km entfernten Bienenständen der Umgebung gekommen sein können.

Das allein ist ein eindrucksvoller Beweis für die Unbrauchbarkeit einer solchen Belegstelle. Deshalb gaben wir auch die Belegstelle Hohe Mark in dieser Form auf.

\section{d) Wann im Jahr erscheinen die ersten und die letzten Drohnen auf den Sammelplätzen?}

Im Jahre 1969 suchten wir festzustellen, wann sich im Frühjahr die ersten und Ende des Sommers die letzten Drohnen auf den Sammelplätzen zeigen. Es war ein spätes Jahr. Überall hatten sich die Bienenvölker schlecht entwickelt, viele waren eingegangen.

Am frühen Nachmittag des 6-5, als bei heiterem Wetter die Lufttemperatur 19-20 betrug, fanden sich auf den Sammelplätzen C, A und E noch keine Drohnen ein. Aber am 12-5, bei ungewöhnlich warmer Lufttemperatur von $20-25^{\circ}$ hörte man bei C ein starkes Summen, und in der Zeit von 14.20-14.35 Uhr erschienen bei der Königin am Ballon 5-10-15-20-7 Drohnen. Am 13.5 war es ebenfalls sehr warm. Trotzdem erschienen auf dem Sammelplatz C nur vereinzelte und auf den Plätzen $B$ und D keine Drohnen. 10 Tage später, am 23-5 fanden sich bei $C$ bis zu 25 Drohnen, bei A und E keine. Auf dem letzten zeigten sich einzelne Drohnen erst am 27-5.

Was das Ende des Drohnenfluges betrifft, so war es offenbar am 20-8 
noch nicht ganz gekommen. Bei bedecktem Himmel, jedoch warmem Wetter flogen bei $\mathrm{C}$ vereinzelte Drohnen die Versuchskönigin an.

Ergebnis :

Die geprüften Drohnensammelplätze wurden von Mai bis August von den Drohnen besucht.

\section{e) Unregelmäßigkeiten im Besuch der Drohnensammelplätze}

Nicht immer ließen sich die Drohnen aufd en Sammelplätzen gleich gut anlocken. Es fiel auf, daß sie manchmal aus unerklärlichen Gründen nicht erschienen. Wenn nach langer Kälteperiode ein schöner, heißer Tag kam, flogen sie in großer Zahl. An den weiteren, vielleicht noch heißeren Tagen blieben sie weg.

Am 10- und 11-8-1966 herrschte nach langer Zeit endlich wieder Versuchswetter. Die Lufttemperatur betrug $22^{\circ}$. Nun flogen die Drohnen wieder. Als es am 12-8 sehr heiß wurde, über $30^{\circ}$, herrschte auf dem Sammelplatz C um 16 Uhr mit etwa 40 angelockten Drohnen stärkster Flug. Die Drohnen ließen sich z.T. bis zur Höhe der Baumkronen herunterziehen.

Am 13-8 stieg das Thermometer auf $34,7^{\circ}$. Es war der heißeste Tag des Jahres! Dazu wurde es windig. Da überraschte es sehr, daß wir im krassen Gegensatz zum vorhergehenden Tag auf Platz $C$ und E nur 1-2 und auf B nur 4-7 Drohnen anlocken konnten.

Am 14-8 hatte es sich abgekühlt. Die Lufttemperatur betrug noch $25^{\circ}$. Nur wenige Drohnen flogen die Versuchskönigin auf den Sammelplätzen B, $\mathrm{E}$ und $\mathrm{C}$ an. In den Drohnenvölkern der Belegstelle befanden sich 800-1000 Drohnen. Drohnenmangel konnte also nicht die Ursache des geringen Fluges sein. Auch später nahm der Drohnen flug nicht mehr sonderlich zu.

Ähnliche Beobachtungen wurden auch von $F$. und H. RUTTNER gemacht (pers. Mttlg.).

Ergebnis :

An manchen Tagen besuchten die Drohnen die Sammelplätze offenbar infolge zu großer Hitze so gut wie nicht.

\section{B. - WERDEN DIE DROHNEN AUCH BEI IHREM STANDPLATZ VON DEN KÖNIGINNEN ANGELOCKT ?}

Bei den Drohnensammelplätzen beschränkt sich die drohnenanlockende Wirkung der Königinnen auf einen begrenzten Kreis. Außerhalb dessen lassen die Drohnen plötzlich von der Verfolgung der Königinnen ab (F. u. H. Rutrner 1965). Die Frage ist, ob die Königinnen nicht dennoch auch außerhalb der 
Drohnensammelplätze Drohnen anziehen, z.B. auf den Flugstraßen oder bei den Standplätzen der Drohnen.

Bereits Hruschка (1868) fand, daß bei einem Bienenstand schon in $5 \mathrm{~m}$ Höhe bis zu 6 und 8 Drohnen von einer an einer Angel fliegenden Königin angelockt werden können. ZMarLicki und MorSe (1963) erhielten bei einem Bienenstand von 40 Völkern und bei einem zweiten Stand mit ungenannter Völkerzahl keine Drohnenanlockung, wohl aber $60 \mathrm{~m} \mathrm{bzw.} \mathrm{90-120} \mathrm{m} \mathrm{davon}$ entfernt. Ich habe die Möglichkeit der Anlockung der Drohnen bei ihrem Standplatz ebenfalls geprüft.

\section{a) Versuche und Beobachtungen im Bienengarten}

Nachdem wir 1967 die Drohnenvölker unserer Anstalt von der Belegstelle Linderhof (Obb.) zurückgeholt und im nördlichen Teil des Bienengartens aufgestellt hatten, führten wir hier ab 24-7 eine Reihe von Ballonversuchen durch. Dabei wurden von Versuchsköniginnen, die sich wie gewöhnlich im Käfig befanden, bis zu 25 Drohnen, und von an der Brust mit einem Faden befestigten fliegenden Königinnen bis zu 100 Drohnen angelockt, so daß wir zunächst glaubten, hier einen Drohnensammelplatz gefunden zu haben.

1968 stellten wir 9 Völker mit lederfarbenen $(=$ cordovan $=c d)$ Drohnen an die Südseite des Gartens und erhielten nun hier am 30-6 bei sehr warmem Wetter und leichtem Wind eine sehr gute Verfolgungsreaktion mit bis zu 40 offenbar meist cd-Drohnen. Bei den Wirtschaftsvölkern an der Nordseite des Gartens ließen sich 20 und 30 Drohnen anlocken. Die drohnenanlockende Wirkung der Königinnen war also stets in der Nähe der Bienenstände am stärksten.

Zu Zeiten aber, in denen sich in unserem Anstaltsgarten keine besonders drohnenreichen Völker befanden, ließen sich hier keine oder nur wenige Drohnen anlocken. Das hatte sich am 3- und 10-7-1966 bei warmem Wetter im nördlichen wie im südlichen Teil ergeben. Auch am 18-6-1968 flogen bei windigem Wetter nur 0-7 Drohnen die Versuchskönigin an, während bei dem gleichzeitig geprüften Drohnensammelplatz E bis zu 25 kamen. Bei einem Kontrollversuch im Mai 1969 fanden sich keine Drohnen mehr ein, nachdem wir die meisten Völker aus dem Anstaltsgarten entfernt hatten.

1974 prüften wir die Frage nochmals. Zu diesem Zweck wurden wieder die meisten Völker der Anstalt weggeschafft. Bleiben mußten jedoch 30 Völker und 30 Ableger, deren Fluglöcher wir zur Verhinderung des Drohnenaus fluges mit Absperrgittern versahen. Das geschah an den Vormittagen des 15- und 16-7. Ab 13-15 Uhr prüften wir im Ballonversuch die Drohnenanlockung von Königinnen an 3 verschiedenen Stellen unseres Bienengartens, am zweiten Tag 
dazu auch auf unserem westlichen Nachbargrundstück. Es ergab sich ein jeweils nur sehr vereinzelter bis geringer Drohnenan flug (im Höchstfalle von 5 Drohnen nach längerer Zeit). Zugleich fanden wir überraschenderweise außen am Absperrgitter einiger Völker ermattete Drohnen. Es müssen also doch Drohnen unserer Völker im Freien geflogen sein, wohl infolge zu später oder ungenügender Absperrung, vielleicht auch, weil die Drohnen in fremden Stöcken übernachtet hatten oder von einem der neuen Aufstellungsplätze wieder zurückgekehrt waren. Die Zahl der die Königinnen an fliegenden Drohnen war jedoch so gering, daß man nicht von einem Drohnensammelplatz sprechen kann. Das beweist der Gegenversuch des ersten Tages beim Sammelplatz auf der Marloffsteiner Höhe, wo trotz starkem Wind sofort viele Drohnen (bis zu 30) angelockt wurden, und das beweist auch der Gegenversuch des zweiten Tages im Bienengarten, bei dem die Drohnen der hier verbliebenen Välker nach dem Hauptversuch frei gelassen wurden, worauf sofort - auf allen 4 geprüften Stellen etwa gleich - 20, 25 und 30 Drohnen die Königin am Ballon an flogen.

Also ist dieser Platz kein Drohnensammelplatz. Dennoch wurden die hier beheimateten Drohnen von den Königinnen in großer Zahl angelockt.

\section{b) Systematische Versuche}

Um die gestellte Frage genau zu prüfen, brachten wir im Jahre 1968 7 Drohnenvölker mit zusammen etwa 3000 cd-Drohnen nacheinander auf 5 verschiedene Plätze, von denen wir wußten oder annahmen, daß sie gewöhnlich frei von Drohnenansammlungen waren.

\section{Kahlschlag südwestlich der Hohen Mark}

Der erste Platz war ein Kahlschlag etwa $500 \mathrm{~m}$ südwestlich unserer Belegstelle Hohe Mark (diese bei B, Abb. 1). Hier waren in früheren Jahren keine Drohnen von Königinnen angelockt worden. Auch in diesem Jahr wurde der Platz vor Aufstellung der Drohnenvölker nochmals geprüft. Nur wenige Drohnen wurden gefunden.

Am 28-6-1968 bei warmem, allerdings windigem Wetter, kamen nur einzelne Drohnen : mitten auf der Schonung 1-2, oben am Hang bei einem Überhälter (Föhre) $70 \mathrm{~m}$ vom zukünftigen Standplatz der Völker entfernt 3-4 Drohnen. Auf der Hochebene über dem Hang fanden sich vorn, $100 \mathrm{~m}$ vom Platz der Völker 1-2 Drohnen, mitten auf der Ebene, ca. $150 \mathrm{~m}$ vom Standplatz, keine Drohnen und am Ende der Ebene, etwa $315 \mathrm{~m}$ von den aufzustellenden Völkern, etwas tiefer, jedoch 7-10 Drohnen. 
Am 1-7 14.00 Uhr wurde der Kahlschlag vor dem Versuch nochmals kurz überprüft. Es zeigten sich keine Drohnen. 14.45 Uhr stellten wir die Drohnenvölker auf. Schon 15.15 Uhr konnten etwa 15 Drohnen in $20 \mathrm{~m}$ Höhe angelockt werden. $50 \mathrm{~m}$ hangaufwärts kamen nur 1-5, $20 \mathrm{~m}$ abwärts hingegen 20 Drohnen. Auf der Anhöhe vorn hörte man starkes Summen. In ca. 30 m Höhe ließen sich 15-20 Drohnen anlocken. Ganz hinten am Ende der Ebene waren es immer nur 5-10. Schließlich sammelten sich bis zu 30 oben auf dem Berg, beim Überhälter, in dem ein Ballon mit einer Königin hängen geblieben war. Hier kamen die Drohnen sogar bis zum Erdboden herunter. Die meisten waren ed-farben. Ein Drohn konnte mit der Hand gefangen werden. Er war dunkel. Möglicherweise stammte er dennoch aus den Drohnenvölkern.

Ergebnis :

Auf dem Standplatz der Drohnenvölker lockten die Königinnen die Drohnen wie auf einem Sammelplatz an, aber auch bei einer Stelle in der Nähe des Standplatzes auf der Höhe.

\section{Ebene bei Kosbach}

Nun wurde ein ebenes Gelände ausgewählt. Es bot sich eine günstige Gelegenheit auf freiem Felde zwischen den Ortschaften Kosbach und Häusling.

Am 2-7-68 war es 14.55 Uhr sehr heiß, über $30^{\circ} \mathrm{im}$ Schatten. Zunächst ließen wir den Ballon mit einer Königin hoch. Erst nach einiger Zeit spielten nur 1-2 Drohnen unsere Königin kurz an. Dann öffneten wir die Fluglöcher der 7 Drohnenvölker und wenige Minuten später, um 15.20 Uhr ließen wir den Ballon vor der Flugfront hoch. Kurz danach wurden etwa 15-20 Drohnen angelockt. $50 \mathrm{~m}$ von den aufgestellten Bienenstöcken, Richtung Kosbach, ließ der Drohnenflug nach. Der Käfig mit der Königin hüpfte infolge des starken Windes heftig in der Luft umher. Trotzdem wurden auf der ganzen Strecke bis 16.00 Uhr 1-4-6 Drohnen angelockt. Am Ende des $200 \mathrm{~m}$ langen Feldes wurde der Drohnenanflug wieder reger. Vielleicht handelte es sich hierbei um Drohnen vom Dorf Kosbach.

Um 16.45 Uhr wurde der Ballon nochmals unmittelbar über den Völkern hochgelassen. In $5 \mathrm{~m}$ Höhe und auch tiefer war der Drohnenflug, offenbar infolge des starken Windes, mit etwa 15 Drohnen am besten.

Ergebnis :

Auch bei diesem Versuch bestätigte sich, daß Drohnen bei ihrem Stand Königinnen ähnlich wie auf einem Sammelplatz verfolgen, bei starkem Wind selbst in geringer Höhe über dem Erdboden. Das stimmt mit den Beobachtungen von Butler und Fairey (1964) überein. 


\section{Wiese bei Drohnensammelplatz E}

Diese eine Wiese im Hochwald ist nur etwa $200 \mathrm{~m}$ vom Drohnensammelplatz E (Abb. 1) entfernt. Hier wurden auch in früheren Jahren keine Drohnen gefunden.

Am 3-7-68 war es etwas kühler geworden, aber noch warm, dazu meist heiter. Über dem Hochwald, der die Wiese allseits umgibt, herrschte starker Wind. Vor dem Öffnen der Fluglöcher, von 14.30-14.45 Uhr wurde die Königin nur einmal von einem Drohn ange flogen. Bis 15.17 Uhr wurden nun vor dem Stand meist 1-3, einmal aber auch 7 Drohnen von ihr angelockt. Hinter dem Stand flogen um 15.25 Uhr 7 Drohnen die Königin in typischer Weise an. Links vom Stand wurden $15.30 \mathrm{Uhr}$ in schätzungsweise $30 \mathrm{~m}$ Höhe 15 Drohnen angelockt und kurz darauf stürzten sich in etwa $20 \mathrm{~m}$ Höhe 20-25 Drohnen auf den Käfig mit der Königin.

Ergebnis :

Auch auf dieser Stelle, die nach allen bisherigen Prüfungen kein Drohnensammelplatz ist, sich aber nahe bei einem Drohnensammelplatz befindet, ergab sich zuletzt sogar eine starke Verfolgungsreaktion über den aufgestellten Drohnenvölkern.

\section{Erlangen, Feld an der Ebrardstraße (nördlicher Rand des Schwabachtales)}

Das Feld wird nördlich von Föhrenhochwald begrenzt. Nach den anderen Richtungen ist das Gelände frei. In der Nähe befinden sich 2 kleine Bienenstände mit wenigen Völkern.

Am 4-7-68 war es fast windstill, schwül, Lufttemperature 220. Die am Ballon aufgelassene Königin flogen von 14.40-14.55 Uhr 1-4-7-10 Drohnen an. Der Platz war also von Drohnen beflogen. Wir wollten deshalb den Versuch abbrechen, entschlossen uns aber dennoch den inzwischen aufgestellten 8 Drohnenvölkern den Flug freizugeben. Gleich danach, 14.55 Uhr flogen 30-40 meist cd-Drohnen die Königin in typischen Schwärmen an. Das dauerte bis zum Abbruch des Versuches um 15.15 Uhr.

Ergebnis :

Der Standplatz der Drohnenvölker könnte ein Drohnensammelplatz sein. Der Versuch besagt also nur, daß die Zahl der sich hier aufhaltenden Drohnen durch die eines neu aufgestellten Bienenstandes erheblich erhöht werden kann.

\section{Platz nordwestlich des Schwarzen Weihers (Abb. $1, S z)$}

Hier wurden bisher niemals Königinnen von Drohnen angeflogen. Auch 
am 5-7-68 bei Windstille und über $30^{\circ}$ hoher Lufttemperatur vermochte unsere Versuchskönigin von 14.27 - 14.45 Uhr keine Drohnen anzulocken, auch in grösserer Höhe nicht.

Als 14.45 Uhr die Fluglöcher der 8 aufgestellten Drohnenvölker geöffnet wurden, bildeten sich sofort bei dem vor dem Stand aufgelassenen Ballon kleine Drohnenschwärme von 1 - 2 - 4-6-12 Drohnen. Als der Ballon noch etwas höher gestiegen war, sammelten sich im Laufe der Zeit bis 15.30 Uhr bis zu 20 Drohnen. Hinter dem Stand erschienen sie nur vereinzelt.

Im Jahre 1974, als wir am 5-und 8-7 weiterführende Versuche an diesem Platz anstellten (s.S. 248), bestätigte sich dieses Ergebnis wieder. Über einem Stand von 10 Völkern spielten bis zu etwa 15 Drohnen die Versuchsköniginnen am Ballon in der typischen Weise an.

Ergebnis :

Auch auf diesem Platz, auf dem bei bisherigen Prüfungen keine fremden Drohnen aufgetreten waren, ergab sich sofort ein starker An flug von Drohnen der aufgestellten Völker.

c) Werden die Drohnen über ihrem Stand auch dann von den Königinnen angelockt, wenn sie sich längere Zeit vorher dort einfliegen konnten?

Bei den geschilderten Versuchen hatten wir die Drohnenvölker erst kurz vorher auf den jeweiligen neuen Platz gestellt. Es wäre möglich, daß eben verstellte Drohnen sich zunächst vorwiegend in der Nähe ihres neuen Standortes aufhalten, um sich einzufliegen und nur bei dieser Gelegenheit die ihnen dargebotenen Königinnen an fliegen, später jedoch die Sammelplätze aufsuchen und über ihrem Stande nicht mehr oder nicht mehr so stark auf die Königinnen reagieren.

Folgende Versuche geben darüber Aufschluß :

1. 3 Tage nach Aufstellung der Drohnenvölker am Schwarzen Weiher am 8-7-1968 war der Himmel um 15.00 Uhr zunächst bedeckt. Es ist daher verständlich, wenn eine Königin meist nur von 1 - 2 - 3 - 4, günstigstenfalls von 7 Drohnen ange flogen wurde. Als es noch trüber wurde und sogar einzelne Regentropfen fielen, flogen nur 1 - 2, manchmal 3 - 4 Drohnen die Königin an.

Gegen 16.00 Uhr brach die Sonne durch die Wolkendecke. Man konnte an den Fluglöchern der Völker beobachten, wie ihre Drohnen nun in stärkerem Maße ausflogen. Sogleich erhöhte sich auch die Zahl der Drohnen bei der Königin, die zu $10-15-25$, ja vielleicht sogar 30 den typischen Schwarm 
bildeten. Bei wieder zunehmender Bewölkung ließ der Anflug nach, um sich um 16.00 Uhr bei nochmals stärker hervortretender Sonne wieder zu verstärken.

Die Drohnen ließen sich bis auf 2 - 3 m zum Boden herunterziehen. Von einem kleinen Hügel aus konnte man mit einem Feldstecher die Drohnen von oben erkennen. Ihre gelbbraune Brustbehaarung leuchtete hell in der Sonne auf. Es handelte sich also nur um cd-Drohnen von unserem Stande. Man erkannte das am deutlichsten bei überschaubaren Schwärmchen von etwa 6 Drohnen.

2. 4 Tage nach der Aufstellung, am 9-7-68 betrug die Lufttemperatur nur etwa $20^{\circ}$. Es war trüb und der Himmel gleichmäßig bedeckt, fast windstill. Zwischen 15.30 und $16.00 \mathrm{Uhr}$ wurden in $15-30 \mathrm{~m}$ Höhe anfangs 6 , später weniger, dann wieder bis zu 25 Drohnen angelockt. Es gelang an diesem Tag jedoch nicht, die Drohnen tiefer als bis zu $10 \mathrm{~m}$ Höhe herunterzuleiten.

3. 5 Tage nach der Aufstellung, am 10-7-68 herrschte warmes, sonniges, jedoch windiges Wetter. Ab 14.40 Uhr wurde die Versuchskönigin zunächst im wechselnden Maße verfolgt und zwar von bis zu 6 Drohnen. Um $15.50 \mathrm{Uhr}$ ließen sich die Drohnen nur an einer ganz bestimmten Stelle von den Völkern in etwa $20 \mathrm{~m}$ Höhe in einer Anzahl von $6 \cdot 10-12$ anlocken. Auch an diesem Tag gelang es nicht, die Drohnen zum Erdboden herunterzuholen.

Um 16.00 Uhr erfolgte vergleichsweise ein Versuch auf dem $950 \mathrm{~m}$ entfernten Sammelplatz A. Hier hörte man trotz Wind an einer Stelle ein schwaches Summen. Bis zu 12 Drohnen spielten die Königin in typischer Weise an. Auch hier ließen sich die Drohnen nicht herunterleiten.

\section{Ergebnis :}

Aus diesen Versuchen geht hervor, daß sich über Bienenständen nicht nur unmittelbar nach dem Umstellen Drohnen anlocken lassen, sondern auch später, wenn sich die Drohnen eingeflogen haben. Es scheint, daß sich auf einem solchen Platz nur die Drohnen der aufgestellten Völker aufhalten.

Man hat aber den Eindruck, daß die Drohnen bei schönem, wolkenlosem Wetter weniger zahlreich am Stande bleiben als bei bedecktem Himmel. Es bestätigte sich dabei die frühere Erfahrung, daß sie bei trübem Wetter tiefer fliegen als bei klarem Himmel.

\section{Gesamtergebnis :}

Nach allen Versuchen ist sicher, daß sich die Drohnen auf ihren Standplätzen von den Königinnen in ähnlicher Weise wie auf den Drohnensammelplätzen anlocken lassen. 


\section{C. - PAAREN SICH DIE DROHNEN UND KöNIGINNEN AUCH AUF IHREN GEWÖHNLICHEN NEUTRALEN STANDPLÄTZEN?}

Wenn auch vieles dafür spricht, daß die Paarung bei den Bienen auf den Drohnensammelplätzen erfolgt, so muß eine systematische Untersuchung der Frage nach dem Paarungsort doch auch alle sonstigen Möglichkeiten in Betracht ziehen. Im folgenden wurde geprüft, ob sich die Drohnen und Königinnen auf ihren Standorten paaren, und zwar auf solchen zunächst, die, wie gewöhnlich, keine Drohnensammelplätze sind. Daß sich die Drohnen auf diesen Plätzen von den Königinnen anlocken lassen, wurde bereits festgestellt. Zu untersuchen bleibt erstens, ob sich hier die Drohnen auch zur Paarung bereit finden, und zweitens, ob sich hier die Königinnen bei starkem Drohnenaufgebot begatten lassen.

\section{I. - Sind die Drohnen auf ihren neutralen Standplätzen paarungsbereit?}

Die Paarungswilligkeit der Drohnen läßt sich nach einer Methode von GARY (1963) prüfen. Er bekam Kopulationen, wenn er die Stachelkammer der Königinnen künstlich offen hielt oder eine geöffnete Stachelkammer vortäuschte. Ungewiß ist, ob er zu diesem Erfolg auf einem Drohnensammelplatz oder auf einem neutralen Platz kam. Wir führten solche Versuche sowohl auf zwei neutralen Plätzen wie vergleichsweise auf verschiedenen Drohnensammelplätzen durch.

\section{Methode :}

Die Stachelkammer einer toten oder nahezu toten begatteten oder unbegatteten Königin wurde mit Hilfe einer feinen auf $31 / 2 \mathrm{~mm}$ gekürzten Insektennadel, eines sog. Minutienstiftes, aufgespreizt. Die Nadel stachen wir von unten her in die Rückenschuppe ein. Um ein völliges Durchstoßen zu verhindern, hatten wir dieser ein winziges Stück Gummi etwas unterhalb der Spitze aufgesteckt. Mit ihrem unteren Ende stellten wir sie auf die Bauchschuppe. Aufgehängt wurde die Königin an der Brust. Durch ein Zeichenplättchen (aus Opalith) zogen wir ein am Ende etwas breit geklopftes Stück Rähmehendraht. Hieran klebten wir die Königin mit dem Brustschild fest. Bald zeigte sich, daß es auch genügt, die Königin mit diesem $0,3 \mathrm{~mm}$ starken Draht an der Wespentaille festzuklemmen. Zur Anlockung von Drohnen ließen wir zunächst. junge Königinnen in kleinen Drahtkäfigen am Ballon aufsteigen. Dann wurde der Versuch durchgeführt.

\section{a) Versuche auf neutralen Standplätzen \\ Bienengarten der Erlanger Anstalt}

1. 27-7-1967 Zum Versuch diente eine 1 Jahr alte, begattete, offensichtlich kranke Königin, die sich nur schwach bewegte. Sie war nach 2 stündigem Trocknen der Verklebung eingegangen und ließ den Hinterleib nach unten hängen. Zuvor waren zur Anlockung von Drohnen 2 Königinnen in Käfigen in ca. $15 \mathrm{~m}$ Höhe gelassen worden. Etwa 40 Drohnen flogen sie an. Die nun daneben aufgehängte tote Königin fand zunächst kaum Beachtung, auch nicht, als die beiden Königinnen weggenommen wurden. Plötzlich sah man durch das 
Fernglas, dåß ein Drohn, offensichtlich tot, mit ihr verhängt war. Der Vorgang war blitzschnell erfolgt. Das Pärchen trennte sich nicht.

2. 29-7-1967 Eine über Nacht infolge $\mathrm{CO}_{2}$ - und Äthernarkose nahezu abgestorbene Königin wurde in der gleichen Weise dicht unter dem eine lebende Lockkönigin enthaltenden Drahtkäfig ca. $20 \mathrm{~m}$ hoch in die Luft gehängt. Nur einzelne Drohnen flogen die Königin an. Plötzlich war ein Drohn mit ihr verhängt.

3. 31-7-1967 Man konnte beobachten, daß die Drohnen hauptsächlich die Königin im Käfig anspielten. Nachdem wir sie entfernt hatten, wandten sich die Drohnen mehr der toten Königin am Draht zu, die sofort von 5 - 7 Drohnen angespielt und alsbald begattet wurde. Bei hängendem Drohn erfolgte keine weitere Begattung. Schnitt man den Endophallus durch oder beließ man nach manchmal auch von selbst erfolgter Trennung das Begattungszeichen, so konnten noch 1-2 Begattungen folgen. Nachdem 2 - 3 Begattungszeichen vorhanden waren, erfolgte keine weitere Verhängung mehr. Die ersten beiden Begattungszeichen wurden anscheinend von den späteren nach oben gedrängt. Bei jedmaligem Entfernen des Drohns und des Begattungszeichens wurde die tote Königin im Laufe des Nachmittags 16 mal begattet. In einem Falle kam es zu einer Einstülpung des Endophallus seitlich zwischen die Hinterleibsringe der Königin.

Weitere Kopulationen erfolgten am 1. und 2-8-1967 am gleichen Ort. Es fiel auf, daß nicht sofort ein Drohn aus dem Drohnenschwarm gewissermaßen im Wettbewerb die Begattung vollzog, sondern daß in der Regel ein einzelner ganz unerwartet zur Begattung kam.

\section{Schwarzer Weiher (Abb. 1, Sz)}

Weitere Versuche dieser Art führten wir im Jahre 1974 nordwestlich des Schwarzen Weihers durch, wo wir schon 1968 einen der Versuche zur Drohnenanlockung über Bienenständen auf neutralen Plätzen angestellt hatten (s.S. 245). Hier war also auch nach damaliger Erfahrung kein Drohnensammelplatz. Wir stellten 10 Versuchsvölker mit einer normalen mäßigen Anzahl Drohnen auf.

1. Am 8-7-1974, bei kühlem, windigem Wetter mit wechselnder Bewölkung spielten auf diesem sehr geschützt liegenden Platz ebenso wie auch schon an den Tagen vorher bis zu etwa 15 Drohnen die lebende Königin im Käfig und die halb tot mit aufgespreizter Stachelkammer darunter hängende in typischer Weise an. Wenn wir es richtig erkannt haben, kam es schon bald zu einer Verhängung, jedoch löste sich der Drohn, ehe das mit Sicherheit festgestellt werden konnte, und fiel leblos herab. Die Stachelkammer der Königin 
mußte darauf wieder aufgespreizt werden. Etwa 45 Minuten später kam es dann zu einer eindeutigen Paarung. Das verhängte Pärchen konnte sichergestellt werden.

2. Am 15-7-1974 wurde der Versuch wiederholt. Sofort nach dem Ballonaufstieg wurden die beiden Königinnen angespielt. Nach mehr als 20 Minuten wurde die frei hängende, die vorher auf dem Drohnensammelplatz Marloffstein begattet worden war, nochmals begattet, jedoch erfolgte die Kopulation nicht in die bereits durch das Begattungszeichen verstopfte Stachelkammer, sondern außerhalb zwischen Brust und Hinterleib der eingekrümmten Königin.

3. Um ganz sicher zu gehen, daß diese Stelle am Schwarzen Weiher kein Drohnensammelplatz ist, prüfte ich sie am 22-7-1974 nach Abtransport der 10 Drohnenvölker nochmals. Wieder, wie in früheren Jahren, vernahm man hier weder ein Drohnensummen noch zeigte sich in der Zeit von 13.50 - 14.10 Uhr in der Höhe von $10-40 \mathrm{~m}$ (Lufttemperatur $20^{\circ}$, leichter Wind) bei der Königin am Ballon auch nur ein einziger Drohn. Bei unseren etwa $1150 \mathrm{~m}$ entfernten bei $B$ stehenden 10 Bienenvölkern aber flogen die Drohnen ein und aus, bei dem gleich daran anschließend zum Vergleich geprüften Drohnensammelplatz C vernahm man ein eindeutiges Drohnensummen, und bei der gleichen Königin stellten sich dort am Ballon sofort bis zu 10 Drohnen gleichzeitig ein.

\section{Ergebnis :}

Somit sind genügend Beweise dafür erbracht, daß die Drohnen auch an neutralen Stellen, die keine Sammelplätze sind, imstande und bereit sind, sich mit Königinnen mit geöffneter Stachelkammer zu paaren.

\section{b) Vergleichsversuche auf Drohnensammelplätzen}

Auf dem Drohnensammelplatz A wurden am 31-7-1968 zwei Kopulationen erzielt, auf dem Drohnensammelplatz Marloffstein (Wasserturm) am 21-7-1972 zwei, am 15-7-1974 eine und auf einem Drohnensammelplatz in Lunz am See (Niederösterreich) Ende Juli 1972 eine. Der Vorgang erfolgte hier anscheinend meist schneller als auf neutralen Plätzen.

Ergebnis :

Die Drohnen sind auf Drohnensammelplätzen wie auf neutralen Plätzen zur Paarung imstande und bereit.

II. - Lassen sich die Königinnen auf ihren neutralen Standplätzen begatten?

Da sich also die Drohnen bei ihren Standplätzen ähnlich wie auf den Drohnensammelplätzen von den Königinnen in großer Zahl anlocken lassen 
und hier sogar mit Königinnen mit künstlich aufgespreizter Stachelkammer kopulieren, somit zur Paarung bereit sind, ist die Möglichkeit nicht von der Hand zu weisen, daß sich auch die Königinnen bei den Standorten der Drohnen begatten lassen.

Ob die Königinnen dazu die Drohnenstände aufsuchen, wurde hier nicht geprüft, wohl aber, ob Königinnen, die bei einem drohnenreichen Bienenstand aufgestellt werden, in dessen Nähe bleiben und sich vielleicht gar mit den Drohnen ihres eigenen Volkes paaren, wie oft behauptet worden ist, oder ob sie weiter fliegen. Zu dieser Frage liegen bereits Ergebnisse anderer Versuchsansteller vor.

Bei einem Versuch von Peer und Farrar (1956) wurden bei einem Stand von 50 Drohnenvölkern stehende Königinnen zu $10 \%$ ausschließlich von deren Drohnen begattet. Aber auch die his zu 1,6 km entfernt aufgestellten Königinnen paarten sich im selben Hundertsatz rein. Bei H. und F. Rutrners Versuchen (1972) lag das Reinpaarungsergebnis unter $10 \%$. Hierin sind allerdings auch Werte von auf Drohnensammelplätzen stehenden Königinnen enthalten.

Bei den zahlreichen Belegstellenprüfungen (s. z. B. Maul 1972) handelt es sich im Grunde zumeist um die gleichen Versuche. Wenn fremde Drohnen in der weiteren Umgebung der miteinander zu paarenden und auf einem Platz aufgestellten Königinnen und Drohnen standen, gab es fast ausschließlich Mischpaarungen.

Da bei diesen Versuchen mit Ausnahme derer von $H$. und F. Ruttner keine Klarheit über die Herkunft der über den Drohnenvölkern fliegenden Drohnen bestand, führte ich einen Versuch durch, bei dem diese Unsicherheit ausgeschaltet war.

\section{Methode :}

Die hier gestellte Frage, ob sich die Königinnen bei ihrem Aufstellungsplatz paaren, läßt sich genetisch mit Hilfe des cordovan-Testes prüfen. Lederfarbene (= cordovan $=$ cd-) Königinnen zeugen bei Paarung mit cd-Drohnen weibliche cd-Nachkommen. Erweisen sich die Töchter (Arbeiterinnen) der Königinnen als ganz oder zum Teil normalfarben ( $\mathrm{nf}=$ dunkel), obschon bei ihren Standplätzen zur Paarungszeit nur ed-Drohnen flogen, so müssen sich die Königinnen zu den Paarungen von dieser Stelle stets oder mindestens einmal entfernt haben.

\section{a) Paarungsversuch}

Nordwestlich des Schwarzen Weihers (Abb. 1, Sz, etwa 900 m südsüdöstl. von $A$ ), wo bei wiederholten Ballonversuchen noch in keinem Fall ortsfremde Drohnen angelockt wurden, und sich somit kein Drohnensammelplatz befindet, stellten wir 196820 junge cd-Königinnen zur Begattung auf, dazu 3000 cdDrohnen (etwa 2560 in 7 Völkern und 440 in 10 der Einwabenkästchen mit den Königinnen). Um ein Verbleiben der Königinnen auf diesem Platz zu 
begünstigen, kürzten wir bei $10 \mathrm{Königinnen} \mathrm{die} \mathrm{beiden} \mathrm{Vorderflügel} \mathrm{gleichmä-}$ Big um etwa $1 \mathrm{~mm}$.

\section{1. Überprüfung der Drohnenpopulation}

Erst 14 Tage später (am 28-7-1968) erlaubte das Wetter Paarungs flüge bei einer Temperatur von etwa $20^{\circ}$. Auch erst dann ließ sich der Drohnenbestand im Luftraum über diesem Platz durch Ballonversuche prüfen. Es war windig, anfangs heiter, später z. T. bewölkt. Als der Himmel sich trübte, gelang es, Schwärme von Drohnen bis zum Erdboden herunterzuziehen. 37 Drohnen wurden mit der Hand gefangen. 36 davon waren cd-Drohnen, 1 war nf (normalfarben). (Die abgefangenen Drohnen stülpten bei kräftigem Druck bis auf einzelne ihren Geschlechtsapparat nicht aus.) Zwei heruntergelotste Schwärme von etwa 12 und etwa 15 Drohnen konnten genau beobachtet werden : Sie bestanden sämtlich aus cd-Drohnen. Somit waren von etwa 64 Drohnen 63 lederfarben und nur einer normalfarben.

Am folgenden Tag, bei etwas wärmerem Wetter, bei Wind und zeitweise starker und anhaltender Bewölkung konnten wir von $14.30-15.30 \mathrm{Uhr}$ 52 Drohnen mit einem Käscher abfangen. 50 waren lederfarben, 2 waren dunkel.

Daraufhin wurden am Vormittag des 30-7 die Drohnenvölker genau durchgesehen und 15 normalfarbene Drohnen gefunden und ausgefangen. Dieses Auftreten von vereinzelten nf-Drohnen in Völkern mit cd-Königinnen haben wir auch schon früher beobachtet. Da diese Drohnen z. T. noch sehr jung gewesen, d.h. erst vor kurzem geschlüpft waren, handelte es sich sicher nicht um zuge flogene Drohnen, sondern um Drohnen, die höchstwahrscheinlich von Eiern der dunklen Arbeitsbienen dieser Völker stammten. Hielten wir doch in diesen Drohnenvölkern meist fehl- oder mischbegattete cd-Königinnen. (Die Brutentwicklung ist in solchen Völkern gewöhnlich besser als in Völkern mit homozygoten cd-Arbeitsbienen).

Danach versuchten wir wieder Drohnen aus der Luft zu fangen. Jedoch ließen sich nun die Drohnenschwärme nicht bis in Bodennähe bringen. Es herrschte Hochdruckwetterlage. Das war auch am folgenden Tag der Fall.

Am 1-8 aber, bei zeitweise leicht bedecktem Himmel, folgten die Drohnen der Königin am Ballon wieder bis zum Erdboden. 22 konnten mit dem Käscher gefangen werden. Es waren ausschließlich lederfarbene Drohnen. Chloroformnarkose bewirkte bei allen das teilweise Ausstülpen ihres Geschlechtsapparates. Zusätzlicher Druck ergab vollständiges Ausstülpen mit Sperma in allen Fällen. Die Drohnen waren also sämtlich geschlechtsreif. (Auf Druck allein hatten die Drohnen nicht ausgestiulpt. Das Abreißen des Kopfes bewirkte bei keiner der wenigen so geprüften ein Ausstülpen.)

Zwei Nebenbeobachtungen sind von Interesse : Beobachtet wurde ein 
Drohnenschwärmchen, welches in 5 - $6 \mathrm{~m}$ Höhe hinter einem kleinen Insekt, möglicherweise einer Arbeitsbiene, oder einer kleinen, vielleicht ihren Orientierungs flug haltenden Königin herflog. Beobachtet wurde auch ein Drohnenschwärmchen, das in großer Höhe über den Föhrenhochwald in westliche Richtung zog.

\section{Nachkommenschaftsprüfung}

12 der aufgestellten cd-Königinnen wurden begattet. Die Arbeiternachkommenschaft der einzelnen Königinnen erwies sich nur zum Teil als lederfarben, hatte also nur zum Teil den Vater vom Standplatz und zwar in folgendem Prozentsatz : $0 \%, 0 \%, 20,3 \%, 23,1 \%, 27,1 \%, 32,2 \%, 42,1 \%, 58,5 \%$, $67,3 \%, 75,7 \%, 84,3 \%, 93 \%$.

$\mathrm{Zu} 100 \%$ rein begattet war somit keine Königin, 2 waren vollkommen fehlgepaart, 10 mischgepaart. Von den Arbeiternachkommen aller Königinnen zusammen waren nur $43,6 \%$ lederfarben, d.h. 56,4\% dunkel.

Ergebnis : Die Königinnen hatten sich also sämtlich auch mit normalfarbenen, d.h. (von wenig wahrscheinlichen Einzelfällen abgesehen) mit ortsfremden Drohnen in mehr oder weniger großer Zahl gepaart, hatten also alle zur Paarung ihren Standort wenigstens einmal verlassen und waren nicht oder nicht ausschlieBlich hier begattet worden. Als Ort der Paarung können wir somit den gemeinsamen Standplatz der Königinnen und Drohnen zumindest für die überwiegende Zahl der Fälle ausschließen.

\section{b) Vergleichsversuch}

Vergleichsweise hatten wir auf dem Sammelplatz A (900 m nordnordwestlich) einige cd-Königinnen zur Begattung aufgestellt, dazu die hier fliegenden Drohnen untersucht.

\section{1. Überprüfung der Drohnenpopulation}

Da sich die Drohnen hier wegen der hohen Bäume nicht in greifbare Höhe herunterlocken ließen, wurde eine andere Methode angewandt : Wir befestigten unter dem Königinnenkäfig ein etwa $20 \mathrm{~cm}$ langes Stück cines Leim fliegenfängers. In der nächsten halben Stunde fingen wir daran $10+6+4+7=27$ Drohnen, von denen 20 lederfarben und $7(=2+2+1+2)$ normalfarben waren.

Rund $2 / 3$ der hier fliegenden Drohnen waren also von dem $900 \mathrm{~m}$ südsüdöstlich gelegenenen Aufstellungsplatz gekommen, 1/3 von den Ständen der Umgebung aus mindestens $2-3 \mathrm{~km}$ Entfernung. 
Nur 2 Drohnen stülpten auf Druck ihren Geschlechtsapparat aus, bei Chloroformbetäubung jedoch fast alle und bei anschließend seitlichem Druck geschah das stets vollständig. Diese Reaktion schien hier etwas besser als bei den Drohnen am Schwarzen Weiher zu erfolgen. Somit waren die Drohnen hier sämtlich geschlechtsreif.

\section{Nachkommenschaftsprüfung}

Von 4 hier in Eiablage getretenen cd-Königinnen erwies sich eine als rein gepaart, die anderen hatten $58,1 \%, 73,7 \%$ und $87,3 \%$ lederfarbene Nachkommen. Im Mittel stammten $80 \%$ der Arbeiter-Töchter dieser Königinnen von den am Schwarzen Weiher, d.h. $900 \mathrm{~m}$ entfernt stehenden cd-Drohnen ab. Trotz so weiter Entfernung der Drohnen vom Standort der Königinnen und Anwesenheit von ca. $30 \%$ dunklen Drohnen im Luftraum über diesem Platz ergab sich hier ein besseres Reinpaarungsergebnis als bei gleichem Standort beider Geschlechtstiere mit ausschließlich cd-Drohnen im Luftraum.

Ergebnis : Die geringe Zahl der verwendeten Königinnen und der abgefangenen Drohnen läßt zwar einen sicheren Schluß nicht zu, doch bestärkt der Versuch in dem obigen Ergebnis (s.S. 252), daß die Königinnen sich keineswegs vorzugsweise auf ihrem Standort paaren, geschweige denn nur mit den Drohnen ihrer eigenen Völker.

Gesamtergebnis : Die Drohnen sind auch bei ihrem neutralen Aufstellungsplatz paarungslustig, die Königinnen sind jedoch hier weniger zur Paarung bereit.

\section{D. - PAAREN SICH DIE KÖNIGINNEN AUF IHREN STANDPLÄTZEN, WENN DIESE DROHNENSAMMELPLÄTZE SIND?}

Die nächste Frage ist, ob Königinnen, die auf Drohnensammelplätzen stehen, sich vorwiegend dort paaren. Diese Möglichkeit liegt nahe, wenn man voraussetzt, daß die Drohnensammelplätze Paarungsplätze sind. Durch Paarungsversuche mit cd-Königinnen und cd- und nf-Drohnen suchten wir eine Antwort auf diese Frage zu erhalten.

\section{a) Paarungsversuche}

\section{Methode :}

Auf den drei Drohnensammelplätzen A, C und E stellten wir in 3 Versuchsjahren (19701972) junge cd-Königinnen zur Begattung auf (Abb. 1). Auf dem Sammelplatz A kamen dazu cd-Drohnen (in Völkern). Damit wollten wir erreichen, daß auf diesem Platz neben den an sich vorhandenen nf-Drohnen viele cd-Drohnen, auf den beiden anderen Plätzen aber verhältnismäßig wenige flogen. Auch deshalb hatten wir den Sammelplatz A als Aufstellungsplatz für die Drohnenvölker gewählt, weil er in einem kleinen Tal liegt, auf diese Weise etwas abgeschlossen 
ist, und offenbar von den Drohnen der Umgebung weniger zahlreich besucht wird, was vielleicht die Paarung der hier aufgestellten Geschlechtstiere untereinander begünstigen könnte.

Wenn sich die auf den Drohnensammelplätzen aufgestellten Königinnen überwiegend mit den dort fliegenden Drohnen paaren würden, müßte die Farbe ihrer weiblichen, aus befruchteten Eiern hervorgehenden Nachkommenschaft der Farbe der im Luftraum des jeweiligen Sammelplatzes fliegenden Population von cd- und nf-Drohnen entsprechen.

Ähnliche Versuche auf breiterer Grundlage liegen von H. und F. RUTTNER (1972) vor. Dank günstig an unbewaldeten Stellen liegender Drohnensammelplätze konnten sie deren Drohnenbesuch über Jahre hinaus genau kontrollieren, wobei sie ein etwa gleichbleibendes Verhältnis des Drohnenzufluges von verschiedenen Ständen her fanden. Nach Aufstellung genetisch verschieden gekennzeichneter Drohnen auf diesen Ständen konnten sie aus den weiblichen Nachkommen von im Gebiet verteilt aufgestellter cd-Königinnen auf den Ort ihrer Paarung schließen.

Bei unseren meist über hohen Baumbeständen liegenden Drohnensammelplätzen hingegen, die sich nur sehr schwer auf Herkunft ihrer Drohnen kontrollieren ließen, war es nicht möglich, diese Methode zur allgemeinen Abklärung der Frage nach der Flugweite der Königinnen anzuwenden. U'nser Ziel konnte nur die Prüfung der Teilfrage sein, ob sich die auf einem Drohnensammelplatz aufgestellten Königinnen dort paaren.

Zunächst sei die Untersuchung des auf den drei Sammelplätzen fliegenden Drohnenbestandes geschildert, danach die Prüfung der weiblichen Nachkommenschaft der dort aufgestellten Königinnen. Aus dem Vergleich beider Feststellungen ergibt siciı ue Beantwortung der hier zu entscheidenden Frage.

\section{b) Drohnenprüfung auf den Sammelplätzen}

Auf dem Sammelplatz A hatten wir während der Versuche an geschlechtsreifen cd-Drohnen aufgestellt :

$\begin{array}{llll}1970 & \text { etwa } & 6000 & \text { (in } 8 \text { Völkern) } \\ 1971 & \text { etwa } & 4260 & \text { (in } 4 \text { Völkern) } \\ 1972 & \text { etwa } & 1550 & \text { (in 6 Völkern) }\end{array}$

Auf allen drei Drohnensammelplätzen prüften wir in dieser Zeit durch Probefänge mittels eines Leim-Fliegenfängers (s.S. 252), wieviele cd- und wieviele nf-Drohnen sich hier im Luftraum aufhielten : 1970 auf dem Sammelplatz A und C, 1971 und 1972 auch auf dem für den Drohnenfang besonders ungünstigen Sammelplatz E (Tab. 1).

\section{Im Jahre 1970}

kamen wir erst spät dazu. Am 7-8 konnten wir bei A mit Mühe und Not 7 Drohnen erwischen. Sie waren sämtlich lederfarben. Am 13-8 erreichten wir auf dem Drohnensammelplatz $\mathrm{C}$ bei windstillem Wetter nach derselben Methode die Rekordzahl von 102 Drohnen! 98 davon waren normal - und nur 4 cordovanfarben.

Also herrschten zu dieser Zeit bei $A$ die cd-Drohnen und bei $C$ die $n f$ Drohnen vor, und es ist wenig wahrscheinlich, daß das zu einer früheren Jahreszeit viel anders gewesen sein wird. 
TAв. 1. - Drohnenfänge auf den Sammelplätzen

TABL. 1. - Captures de mâles sur les lieux de rassemblement

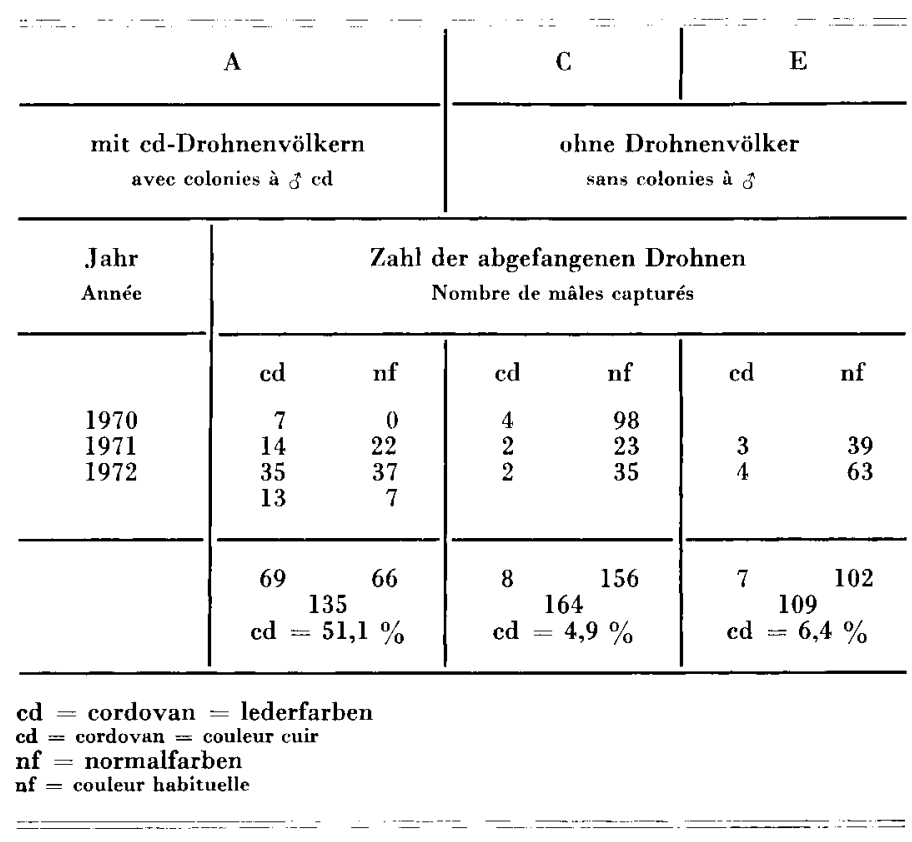

\section{Im Jahre 1971}

überprüften wir die Drohnen aller Sammelplätze bald nach der Aufstellung der Königinnen. Bei A wurden am 5-7 bei 8 Fängen 36 Drohnen eingeholt : 14 waren cd- und 22 normalfarben. Bei $\mathrm{C}$ gingen am nächsten Tag 25 Drohnen auf den Leim. Hier waren nur 2 lederfarben, aber 23 normal pigmentiert. Beim Sammelplatz E fingen wir am 7-7 bei 10 Ballonaufstiegen 42 Drohnen ab. Nur 3 waren lederfarben, 39 dagegen normal.

Somit war auch 1971 der Anteil der cd-Drohnen auf dem Sammelplatz A mit seinen cd-Drohnenvölkern bedeutend höher als auf $\mathrm{C}$ und $\mathrm{E}$.

\section{Im Jahre 1972}

prüften wir die Drohnen aller drei Sammelplätze ebenfalls bald nach der Aufstellung der Versuchsköniginnen Anfang Juli.

Auf dem Sammelplatz A fingen wir bei 10 Ballonaufstiegen 72 Drohnen, und zwar 35 lederfarbene und 37 dunkle. Wir hatten jedoch den Eindruck, als 
ob die normalfarbenen Drohnen ihren Geschlechtsapparat öfter ausstülpten als die lederfarbenen, die vielleicht jünger waren.

Am folgenden Tag flogen die Drohnen bei $C$ in etwa $40 \mathrm{~m}$ Höhe über den Baumkronen. Es gelang nicht, auch nur einen Drohn mit dem Fliegenfänger abzufangen. Am übernächsten Tag war der Drohnen flug mit an die 100 Drohnen hier in mäßiger Höhe sehr stark. Bei 10 Ballonaufstiegen wurden 37 Drohnen gefangen, davon 35 normal-und 2 lederfarbene.

Am 14-7, einem warmen Sommertag, flogen beim Sammelplatz $E$ die Drohnen ebenfalls ca. $40 \mathrm{~m}$ über den Baumkronen. Trotz der großen Höhe konnten bei 8 Ballonaufstiegen 67 Drohnen abgefangen werden : 63 dunkle und nur 4 lederfarbene.

Bei A war am 17-7 bei heißem Wetter (über $30^{\circ} \mathrm{C}$, auch tags zuvor war es schon heiß gewesen) der Drohnen flug sehr schlecht. Am 10-8 wurden die Königinnen hier zunächst ebenfalls nicht, später aber doch sehr stark von den Drohnen angespielt. Bei 8 Ballonaufstiegen konnten 20 Drohnen abgefangen werden : dieses Mal 13 lederfarbene und nur 7 normalfarbene.

Obschon also das Drohnenverhältnis 1972 hier etwas wechselte, lag doch auch 1972 die Zahl der ed-Drohnen beim Sammelplatz A stets wesentlich höher als bei den anderen beiden Sammelplätzen.

\section{Ergebnis :}

Nimmt man die Ergebnisse aller drei Jahre zusammen, so zeigt sich eindeutig, daß die Zahl der auf dem Sammelplatz A fliegenden cd-Drohnen infolge der dort aufgestellten cd-Drohnenvölker regelmäßig bedeutend höher war als auf den Sammelplätzen $\mathrm{C}$ und E. Diese wurden stets von nur wenigen cdDrohnen besucht.

Bei Paarung der Königinnen auf ihren Plätzen müßten also die weiblichen Nachkommen der Königinnen des Sammelplatzes A in größerer Zahl cdCharakter haben als die der Plätze $\mathrm{C}$ und $\mathrm{E}$.

\section{c) Nachkommenschaftsprüfungen}

Auf den 3 Drohnensammelplätzen A, C und E stellten wir in den Versuchsjahren 1970-1972 jeweils in den Monaten Juni und Juli cd-Königinnen zur Paarung auf, von denen 103 in Brut gingen.

Die Prüfung ihrer weiblichen Nachkommenschaft brachte ein auf allen ihren Standplätzen nahezu übereinstimmendes Ergebnis (Tab. 2). Der cdAnteil der Arbeitsbienen aller Königinnen war überall ungefähr gleich. Die Mittelwerte waren nicht sehr unterschiedlich und die Einzelwerte verteilten sich um diese in ähnlicher Weise. Wenn sich die Königinnen ausschließlich auf 
TAB. 2. - Nachkommenschaftsprüfung der cd-Königinnen von den Sammelplätzen

TABL. 2. - Analyse de la descendance des reines cd des lieux de rassemblement

\begin{tabular}{|c|c|c|c|c|c|c|}
\hline \multicolumn{3}{|c|}{$\mathbf{A}$} & \multicolumn{2}{|c|}{ C } & \multicolumn{2}{|c|}{$\mathbf{E}$} \\
\hline \multicolumn{3}{|c|}{$\begin{array}{l}\text { mit cd-Drohnenvölkern } \\
\text { Avec colonies à ơ cd }\end{array}$} & \multicolumn{4}{|c|}{$\begin{array}{l}\text { ohne Drohnenvölker } \\
\text { sans colonies à } \delta\end{array}$} \\
\hline $\begin{array}{l}\text { Jahr } \\
\text { Année }\end{array}$ & $\begin{array}{l}\text { Zahl der } \\
\text { cd- } \\
\text { Königinnen } \\
\text { Nbre de reines } \\
\text { cd }\end{array}$ & $\begin{array}{c}\% \text { weibl. } \\
\text { cd- } \\
\text { Nachkommen } \\
\% \text { descendance } \\
\text { femelle ed }\end{array}$ & $\begin{array}{c}\text { Zahl der } \\
\text { cd- } \\
\text { Königinnen } \\
\text { Nbre de reines } \\
\text { cd }\end{array}$ & $\begin{array}{c}\text { \% weibl. } \\
\text { cd- } \\
\text { Nachkommen } \\
\% \text { descendance } \\
\text { femelle cd }\end{array}$ & $\begin{array}{c}\text { Zahl der } \\
\text { cd- } \\
\text { Königinnen } \\
\text { Nbre de reines } \\
\text { cd }\end{array}$ & $\begin{array}{l}\text { \% weibl. } \\
\text { cd- } \\
\text { Nachkommen } \\
\% \text { descendance } \\
\text { femelle cd }\end{array}$ \\
\hline $\begin{array}{l}1970 \\
1971 \\
1972\end{array}$ & $\begin{array}{r}21 \\
6 \\
8\end{array}$ & $\begin{array}{l}33,6 \\
24,2 \\
29,9\end{array}$ & $\begin{array}{r}11 \\
6 \\
7\end{array}$ & $\begin{array}{l}26,3 \\
36,1 \\
22,3\end{array}$ & $\begin{array}{r}24 \\
13 \\
7\end{array}$ & $\begin{array}{l}30,1 \\
39,7 \\
26,7\end{array}$ \\
\hline $\begin{array}{c}\text { gewogenes } \\
\text { Mittel } \\
\text { moyenne } \\
\text { pondérée }\end{array}$ & 35 & 32,8 & 24 & 27,5 & 44 & 32,4 \\
\hline
\end{tabular}

ihren Standplätzen gepaart hätten, müßte der cd-Anteil ihrer Nachkommen sehr verschieden sein. Er müßte dem der Drohnen in dem jeweiligen Luftraum entsprechen, d.h. auf dem Sammelplatz A etwa $50 \%$, auf den beiden anderen Sammelplätzen aber nur etwa $5 \%$ betragen. Er lag aber im Durchschnitt der Fälle um etwa $30 \%$. Auch aus den graphischen Darstellungen (Abb. 2-4) ersieht man, daß die den cd- und nf-Anteil der Nachkommenschaft der Versuchsköniginnen angebenden Flächen bei allen drei Versuchsplätzen etwa die gleiche Größe haben. Also sind die auf den Sammelplätzen $\mathrm{C}$ und $\mathrm{E}$ bei wenigen cd-Drohnen aufgestellten Königinnen im ganzen keineswegs weniger häufig von cd-Drohnen begattet worden als die auf dem Sammelplatz A mit seinen zahlreichen cd-Drohnen. Und somit ist sicher, daß die Königinnen in ihrer Gesamtheit sich nicht auf ihrem Standplatz gepaart, sondern diesen verlassen haben.

“ Reinpaarungen » (d.h. Paarungen der cd-Königinnen ausschließlich mit cd-Drohnen) kamen nicht vor. Das war bei höchstens $51 \%$ cd-Drohnen, wie sie sich auf dem Sammelplatz A fanden, und bei der verhältnismäßig geringen Zahl von Versuchsköniginnen nicht anders zu erwarten und spricht nicht gegen die Paarung auf den fraglichen Plätzen. Ist doch bei 8-maliger Paarung und bei $50 \%$ igem Anteil der cd-Drohnen mit so gut wie keinen reinen cd-Paarungen zu rechnen (Dreher 1957). 


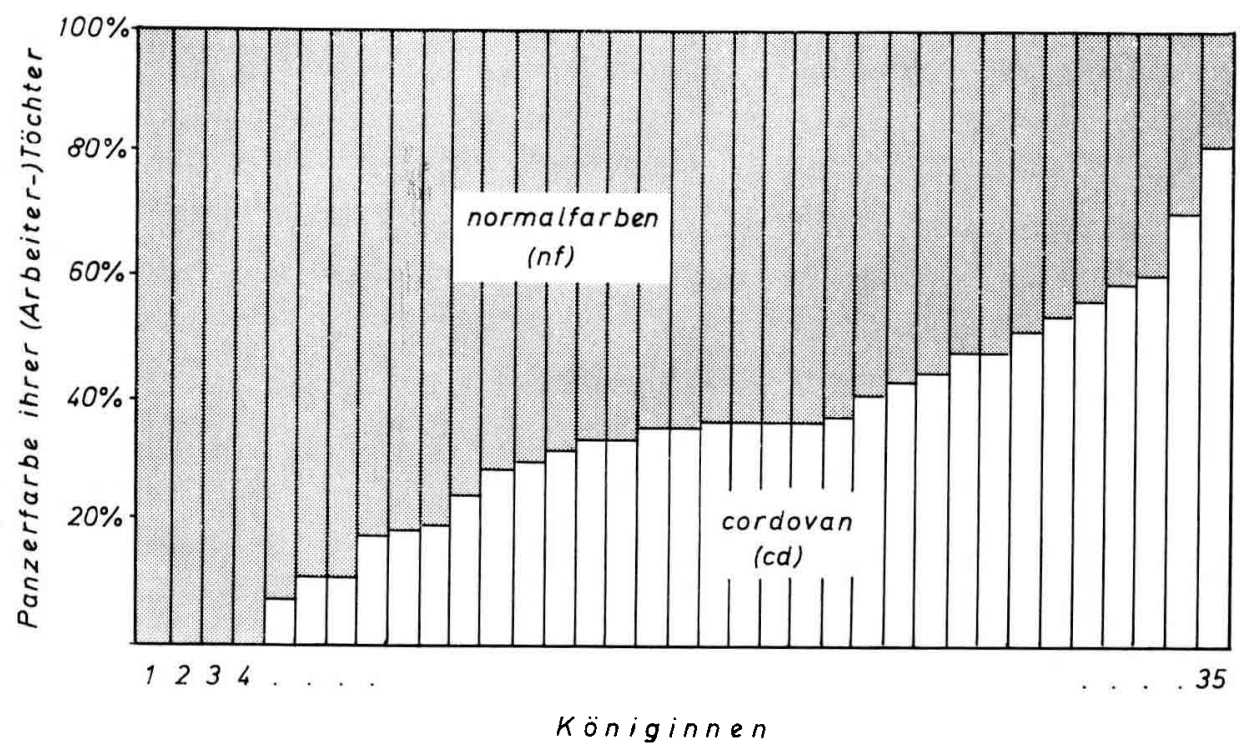

Abb. 2. - Panzerfarbe der weiblichen Nachkommenschaft der 1970-1972 auf dem Drohnensammelplatz A stehenden 35 Königinnen.

Fig. 2. - Couleur de la descendance femelle des 35 reines du lieu de rassemblement A en 1970-1972.

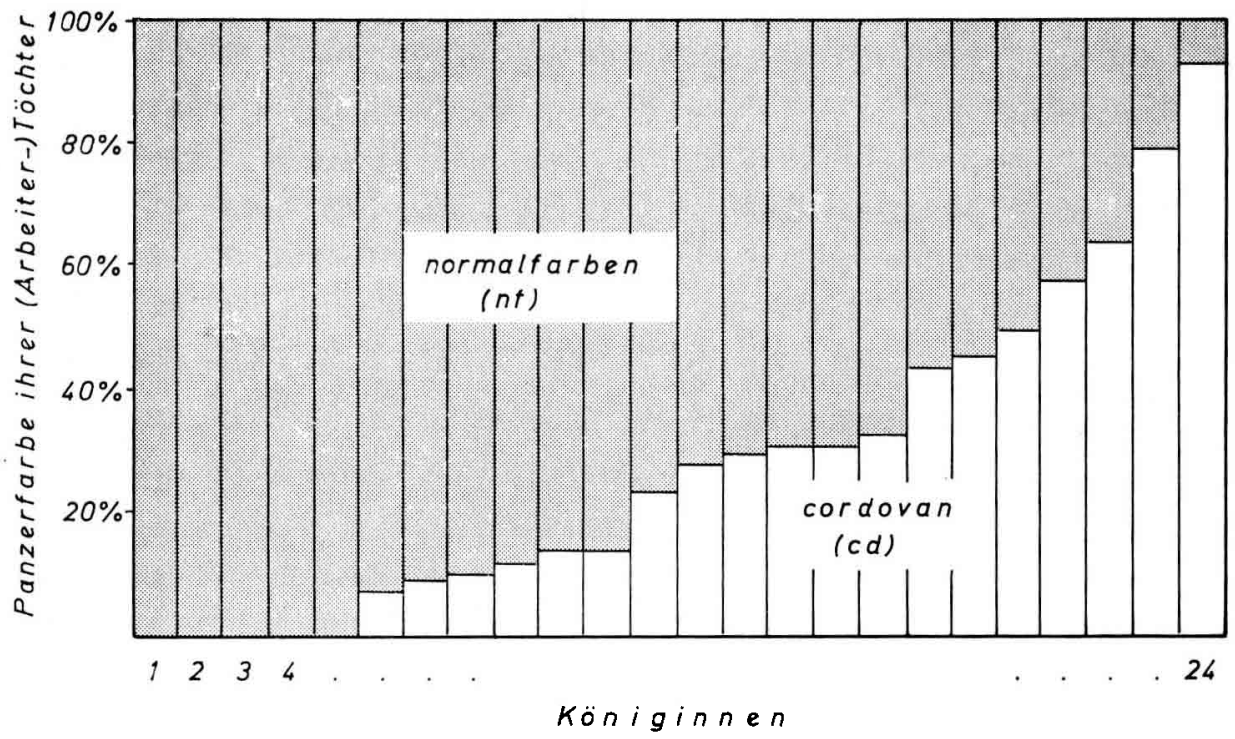

Abb. 3. - Panzerfarbe der weiblichen Nachkommenschaft der 1970-1972 auf dem Drohnensammelplatz C stehenden 24 cd-Königinnen.

Frc. 3. - Couleur de la descendance femelle des 24 reines du lieu de rassemblement $C$ en 1970-1972. 


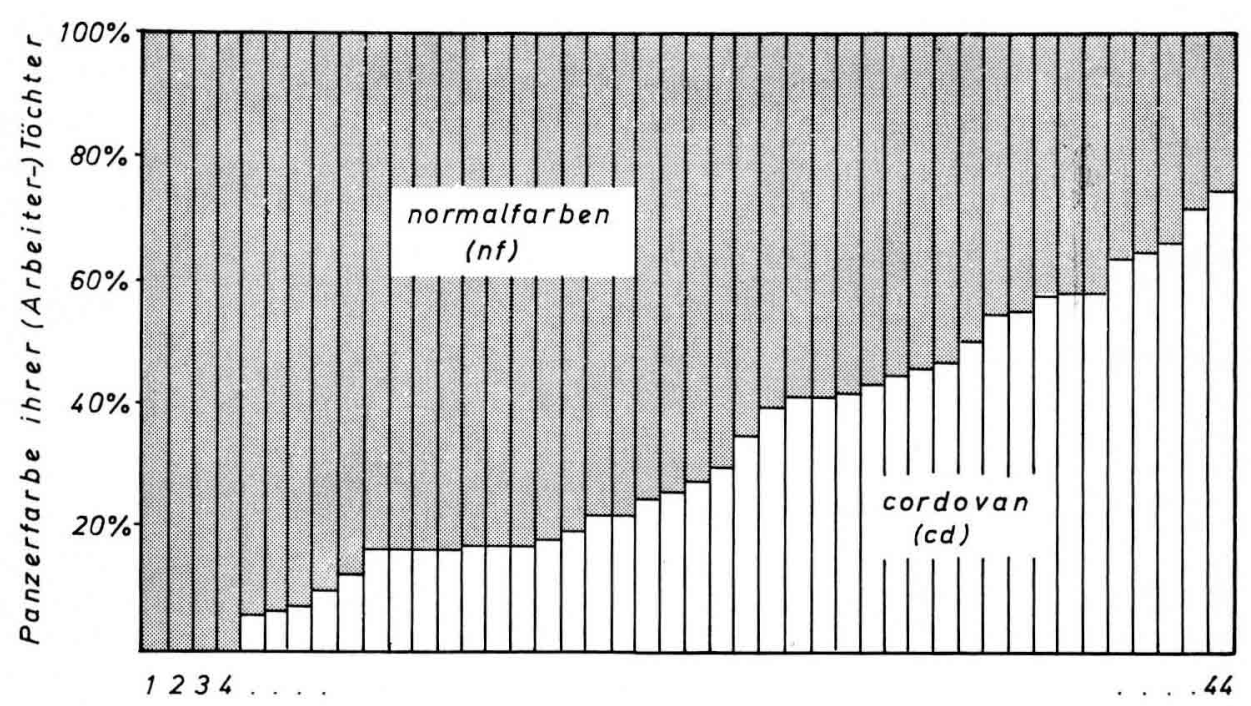

Königinnen

Abb. 4. - Panzerfarbe der weiblichen Nachkommenschaft der 1970-1972 auf dem Drohnensammelplatz E stehenden 44 Königinnen.

Fig. 4. - Couleur de la descendance femelle des 44 reines du lieu de rassemblement $E$ en 1970-1972.

( Fehlpaarungen 》(d.h. Paarungen ausschließlich mit nf-Drohnen) gab es hingegen einige, was bei den Sammelplätzen $C$ und $E$ mit dem starken Ủberwiegen von nf-Drohnen sowohl auf den Plätzen selbst wie wahrscheinlich auch in ihrer Umgebung nicht verwundert. Beim Sammelplatz A hingegen spricht das dafür, daß die Königinnen den Sammelplatz zur Paarung verlassen haben.

“ Mischpaarungen ") (d.h. Paarungen teils mit cd-Drohnen, teils mit nf-Drohnen) waren die Regel und zwar in sehr verschiedenem Verhältnis, doch stark zur normalfarbenen Seite neigend, sowohl insgesamt wie auf jedem der drei Sammelplätze für sich : ebenfalls ein Hinweis, daß sich auch die Königinnen von $\mathbf{A}$ zumeist in Gebieten paarten, in denen die nf-Drohnen in der Überzahl waren.

( Gute » Mischpaarungen mit vielen cd-Drohnen und « schlechte ) mit wenigen kamen auf allen drei Plätzen zustande. Bei einer Königin des Platzes A mit seinen vielen cd-Drohnen ergab sich die zweitbeste Mischpaarung mit 81,1\% cd-Nachkommen. Aber auch bei den Königinnen der beiden anderen Plätze, wo nur wenige cd-Drohnen flogen, gab es gute Mischpaarungen : die beste sogar mit $91,6 \%$ auf $\mathrm{C}$ und die drittbeste mit 74,7\% auf $\mathrm{E}$. Auch das 
bekräftigt das Ergebnis, daß die Paarung außerhalb des Aufstellungsplatzes erfolgte.

Sehr bemerkenswert ist, daß die Ergebnisse der einzelnen Jahre ungefähr einander entsprechen. Nur 1971 ergab sich eine Abweichung. Weiter fällt auf, daß sich die geringere Zahl der Versuchsdrohnen des Jahres 1972 (S. 254) in einem auf allen drei Plätzen geringeren Prozentsatz von lederfarbenen weiblichen Nachkommen bemerkbar macht. Das unterstreicht die Bedeutung der großen Drohnenzahl für das Erreichen der gewünschten Paarungen.

Im einzelnen hatten die Königinnen cd-Arbeiternachkommen in folgenden Prozentsätzen :

1970

Drohnensammelplatz $A: 21$ Königinnen $\overline{\mathbf{x}}=33,6 \%$

$0 \%, 6,9 \% 13,4 \%, 17,2 \%, 18,1 \%, 18,8 \%, 27,7 \%, 31,3 \%, 32,7 \%$, $34,9 \%, 35,0 \%, 36,1 \%, 37,0 \%, 39,6 \%, 44,4 \%, 46,8 \%, 50,0 \%, 50,2 \%$, $53,1 \%, 59,3 \%, 69,4 \%$.

Drohnensammelplatz $C: 11$ Königinnen $\overline{\mathrm{x}}=26,3 \%$ $78,0 \%$.

$0 \%, 0 \%, 8,7 \%, 10,9 \%, 13,4 \%, 27,0 \%, 29,0 \%, 30,5 \%, 43,3 \%, 49,09 \%$,

Drohnensammelplatz $E: 24$ Königinnen $\overline{\mathbf{x}}=30,1 \%$

$0 \%, 0 \%, 6,3 \%, 7,4 \%, 15,7 \%, 15,8 \%, 16,3 \%, 16,9 \%, 16,9 \%, 16,9 \%$, $19,0 \%, 21,2 \%, 21,2 \%, 24,5 \%, 26,6 \%, 41,3 \%, 44,0 \%, 50,0 \%, 54,2 \%$, $54,8 \%, 57,6 \%, 64,1 \%, 64,5 \%, 66,6 \%$.

1971

Drohnensammelplatz $A$ : 6 Königinnen $\overline{\mathbf{x}}=34,2 \%$ $13,5 \%, 29,4 \%, 35,7 \%, 36,1 \%, 55,1 \%$

Keine Königin war rein begattet, aber auch keine völlig fehlgepaart.

Drohnensammelplatz $C: 6$ Königinnen $\overline{\mathbf{x}}=36,1 \%$

$0 \%, 0 \%, 23,2 \%, 45,1 \%, 56,6 \%, 91,6 \%$

Hier fanden sich die stärksten Gegensätze.

Drohnensammelplatz $E: 6+7$ Königinnen $\overline{\mathbf{x}}=37,1 \%$

a) Juni : 6 Königinnen $\overline{\mathbf{x}}=34,1 \%$

$5,4 \%, 9,5 \%, 41,2 \%, 43,2 \%, 47,0 \%, 58,7 \%$

b) Juli : 7 Königinnen $\overline{\mathbf{x}}=39,7 \%$

$0 \%, 15,9 \%, 29,6 \%, 40,5 \%, 45,4 \%, 72,0 \%, 74,7 \%$

1972

Drohnensammelplatz $A: 8$ Königinnen $\overline{\mathbf{x}}=29,9 \%$

$0 \%, 0 \%, 0 \%, 23,9 \%, 32,8 \%, 42,5 \%, 58,7 \%, 81,1 \%$ 
Schien es bisher so, als ob auf diesem Platz völlige Fehlpaarungen selten seien, so war in diesem Jahr mit 3 Fehlpaarungen das Gegenteil der Fall. Wahrscheinlich hängt das mit der geringen Drohnenzahl zusammen.

Drohnensammelplatz $C: 7$ Königinnen $\overline{\mathbf{x}}=22,3 \%$

$0 \%, 7,2 \%, 9,5 \%, 13,6 \%, 32,1 \%, 36,4 \%, 63,1 \%$

Drohnensammelplatz $E$ : 7 Königinnen $\overline{\mathbf{x}}=26,7 \%$

$0 \%, 12,2 \%, 17,9 \%, 25,7 \%, 34,0 \%, 39,2 \%, 58,0 \%$

Ergebnis : Die Zusammensetzung der Nachkommenschaft der Königinnen war auf allen 3 Plätzen nicht sonderlich verschieden und selbst bei geringer Königinnenzahl in den einzelnen Jahren ähnlich. Es ist daher kein Zweifel, daß die auf dem Sammelplatz aufgestellten Königinnen zur Paarung zumeist nicht dort geblieben, sondern weiter geflogen sind. Also sind die Königinnen auf einem Drohnensammelplatz nicht unbedingt paarungswillig, und ein Drohnensammelplatz spielt, wenn überhaupt, für die Auslösung des Paarungsinstinktes bei der Königin nicht die erste Rolle.

\section{E. - WOHIN FLIEgEN DIE KöNIGINNEN ZUR PAARUNG ?}

Nach den vorstehenden Ergebnissen paaren sich die Königinnen nicht oder nur zu einem geringen Teil bei ihrem Aufstellungsort, auch dann nicht, wenn dieser ein Drohnensammelplatz ist. Sie fliegen zur Paarung weiter. Wie weit fliegen sie, und suchen sie dabei andere entferntere Drohnensammelplätze auf?

\section{a) Rückfliegeversuche}

Zur Prüfung dieser Fragen kamen Paarungsversuche wegen der Schwierigkeit, den Drohnenbestand über unserem bewaldeten Versuchsgelände zu kontrollieren, nicht in Frage. Wir waren auf Rück fliegeversuche angewiesen (s.S. 254) : Man läßt die vom Paarungs flug zurückgekehrten Königinnen von verschieden Plätzen aus frei und stellt fest, ob und nach welcher Zeit sie wieder zu ihrem Stock zurückfinden. Auf diese Weise wird offenbar, ob den Königinnen der Platz, auf dem sie frei gelassen wurden, oder dessen Umgebung bekannt war.

Bei Drohnen ergab sich bei allen derartigen bisherigen Versuchen, daß sie sich auf Entfernungen bis zu $5 \mathrm{~km}$, ja sogar $7 \mathrm{~km}$ zurückfinden können (Zander 1923, Alber 1949, Levenetz 1954, Koska 1955, Oentel 1956, KoNopacKa 1968). Indessen behindern Wasserflächen ihren Flug beträchtlich (Meinen 1970).

Daß Königinnen sich wieder zu ihren Völkern auf einige Entfernung 
zurückfinden können, wird gelegentlich von Imkern berichtet. Z.B. verstellte v. Berlepsch (1869) ein Völkchen mit junger Königin. Diese fand sich nach einiger Zeit wieder am alten Orte ein. ZaNDER (1923) berichtet von einer Königin, die $500 \mathrm{~m}$ zu ihrem alten Stand zurück flog. Mein Vater hatte ein ähnliches Erlebnis mit einer gekauften Königin, die ihm entkam und auf eine Entfernung von schätzungsweise $1000 \mathrm{~m}$ wieder zu ihrem Heimatstand zurückfand, und der Imker Schneider in Fellen bei Gemünden berichtete mir von einem Rück flug einer solchen Königin auf $1500 \mathrm{~m}$.

Rück fliegeversuche unternahmen vom Wasser aus zur Greifswalder Oie Evenius (1929), auf dem Festlande von beliebigen neutralen Plätzen Konopacka (1968) und GARY (1971). Nur auf dem Festland kehrten die Königinnen einigermaßen sicher zum Stock zurück, bis auf $500 \mathrm{~m}$ bei GARY's und $800 \mathrm{~m}$ bei KonopacKa's Versuchen. Einzelne Königinnen GarY's kamen bis auf $1600 \mathrm{~m}$ wieder.

In der vorliegenden Untersuchung stellten wir Rück fliegeversuche insbesondere von Drohnensammelplätzen aus an, aber auch von neutralen Stellen, die also keine Sammelplätze waren. Voraussetzung für hinreichend eindeutige Ergebnisse bei solchen Versuchen ist eine große Zahl von Rück flügen. Deshalb führten wir die Versuche 2 Jahre lang (1969 und 1970) mit zusammen 252 Flügen von $188 \mathrm{Königinnen} \mathrm{durch.}$

\section{Methode :}

In Vorversuchen, bei denen wir die Königinnen erst längere Zeit nach ihrem Begattungsflug von einem Käfig aus zurückfliegen ließen, machten wir die Erfahrung, daß sie sich häufig am Ab flugplatz neu orientierten und, statt fortzu fliegen, zu ihrem Käfig zurückkehrten. Das war besonders dann der Fall, wenn sich Arbeitsbienen bei ihnen befanden. Als wir hingegen die mit dem Begattungszeichen zurückkehrenden Königinnen sofort und ohne Begleitbienen zum Versuchsflug verwandten, flogen sie regelmäßig ab, ohne zum Versuchsort zurückzukehren.

Von der Schwierigkeit der Neuorientierung am Käfig berichtet auch Konopacka. GarY hatte sie offenbar nicht, obwohl er die Königinnen erst am Tag nach dem Hochzeits flug zum Rück flug frei setzte.

Besondere Vorrichtungen zum Abfangen der Königinnen verwendeten wir nicht. Wir hefteten nur ein kleines Absperrgitter vor das Flugloch. Wenn sich die Königin hinter dem Gitter zeigte, schoben wir es beiseite und gaben ihr den Ausflug frei. Sodann versperrten wir den Eingang wieder mit dem Gitter. Die mit dem Begattungszeichen zurückkehrende Königin war nun leicht am Flugloch abzufangen.

Die Versuche führten wir ebenso wie die vorhergehenden im Gelände unserer früheren Belegstelle a Hohe Mark » durch. Auf dem in einem kleinen Tal gelegenen Drohnensammelplatz A stellten wir die Versuchsköniginnen auf. Wie die Kartenskizze (Abb. 1) zeigt, gruppieren sich um ihn die 5 weiteren Sammelplätze B, C, D, E, F und die 4 neutralen Ab flugstellen W, X, Y, Z. Von diesen 9 Versuchsplätzen ließen wir die Königinnen zum Rückflug frei.

Die frei gelassenen Königinnen bewegten sich in Spiralen nach oben und verschwanden. Selten kehrte eine Königin zu ihrem Ab flugplatz zurück.

\section{Wiederholte Rückflüge von verschiedenen Plätzen}

Ein erheblicher Teil der Königinnen wurde wiederholt zu Rück flügen verwendet, d.h. von verschiedenen Plätzen aus freigelassen. Werden solche 
wiederholten Flüge die Ergebnisse beeinträchtigen, weil die Königinnen auf diese Weise ihren Flugraum besser kennen lernen? Sicher nicht, sofern die Richtungen, in der die Abflugplätze liegen, weit voneinander getrennt sind. Bei in gleicher Richtung liegenden Plätzen wird das eher möglich sein (S. 273). Aber die Königinnen scheinen sich in erster Linie auf dem Hin flug zu orientieren, weniger auf dem Rück flug. Denn es ist schwer, Königinnen, die infolge ihres Orientierungsfluges nur die nächste Umgebung ihres Stockes kennen, durch immer weitere Rück flüge auf steigende Entfernungen zu dressieren. In entsprechenden Tastversuchen fanden unsere Königinnen nach gelungenen Anfangsdressuren auf kurze Entfernungen ab $400 \mathrm{~m}$ nicht mehr zurück (BöтTCHER u. Mit. 1966).

Für schlechte Orientierung auf dem Rückweg spricht auch, daß einzelne begattete Königinnen, die wir vom gleichen Ort ein zweites Mal zurück fliegen ließen, zu den Rück flügen etwa gleich lange brauchten (Tab. 5 und 11).

\section{b) Ergebnisse}

Die Ergebnisse der Rück flüge von den verschiedenen Plätzen sind im folgenden zusammengestellt und besprochen. Angegeben sind die Rückkehrzeiten der Versuchsköniginnen, gegliedert nach kurzen (bis 10 Minuten dauernden) Rückflügen und nach langen. Dazu werden die nicht zurückgekehrten Königinnen aufgeführt.

Die Werte stammen zumeist aus den Jahren 1969 und 1970. Die des Jahres 1969 sind durch einen Punkt gekennzeichnet. Ein Strich (一) steht für eine Königin, die nicht zum Rück flug zurückkehrte.

54 Königinnen konnten wir von mehreren Plätzen zurück fliegen lassen : 46 von zwei, 7 von drei und 1 von fünf. In diesen Fällen sind über oder unter der Rückkehrzeit vom betreffenden Platz auch die Rückkehrzeiten von den anderen Plätzen sowie deren Kennbuchstaben angegeben. Die Reihenfolge der Flüge läuft von unten nach oben. Allgemein gilt über die Rück fliegeergebnisse folgendes :

Kurze Rückflüge besagen, daß die Königinnen auf einem ihnen bekannten Ort oder nahe bei einem ihnen bekannten Ort freigesetzt wurden. Sie lassen also auf eine gute Kenntnis des geprüften Platzes schließen.

Bei einer Fluggeschwindigkeit von $340 \mathrm{~m}$ in der Minute (Gary 1971) müßte die Königin von einem 600-700 $\mathrm{m}$ entfernten Platz in 2 Minuten, von einem $2000 \mathrm{~m}$ entfernten Platz in 6 Minuten zurückkehren.

So schnelle Rück flüge hatten wir nur vereinzelt und zwar von $D(800 \mathrm{~m}$, Tab. 6) in 2 und 2,5 Minuten, aber schon nicht mehr von $B(600 \mathrm{~m}$, Tab. 4) in 3 (statt 1,8$)$ Minuten, von $\mathrm{E}(950 \mathrm{~m}$, Tab. 7 ) in 7 (statt 2,8) Minuten und 
TAB. 3. - Rüchfliegeversuche : Gesamtaufstellung

TABL. 3. - Expériences de retour : disposition générale

252 Rückflüge von 188 Königinnen zum Standort (Drohnensammelplatz A)

252 vols de retour à l'emplacement du rucher (lieu de rassemblement de mâles A) effectués par 188 reines.

\begin{tabular}{|c|c|c|c|c|c|c|c|}
\hline $\begin{array}{c}\text { von } \\
\text { Drohnen- } \\
\text { sammel- } \\
\text { platz } \\
\text { à partir } \\
\text { du lieu de } \\
\text { rassemb. }\end{array}$ & $\begin{array}{c}\text { von } \\
\text { neutralem } \\
\text { Platz } \\
\text { à partir } \\
\text { de l'endroit } \\
\text { neutre }\end{array}$ & $\begin{array}{c}\text { aus } \\
\text { Entfernung } \\
\text { von } m \\
\text { distance }\end{array}$ & $\begin{array}{c}\text { aus } \\
\text { Richtung } \\
\text { orientation }\end{array}$ & $\begin{array}{c}\text { Anzahl } \\
\text { der Flüge }\end{array}$ & $\begin{array}{c}\text { Anzahl } \\
\text { der zurück- } \\
\text { gekehrten } \\
\text { Königinnen } \\
\begin{array}{c}\text { Nbre de reines } \\
\text { rentrées }\end{array}\end{array}$ & $\begin{array}{c}=\% \\
\%\end{array}$ & $\begin{array}{c}\text { Rückflug } \\
\text { in Minuten } \\
\varnothing \\
\begin{array}{c}\text { Durée du vol } \\
\text { de retour } \\
\text { en mn }\end{array}\end{array}$ \\
\hline \multirow[t]{3}{*}{$\begin{array}{l}\mathbf{B}^{+} \\
\mathbf{C}^{+++} \\
\mathbf{D}^{+} \\
\mathbf{E}^{++}\end{array}$} & & $\begin{array}{l}600 \\
650 \\
800 \\
950\end{array}$ & $\begin{array}{l}\text { SW } \\
\text { NW } \\
\text { SO } \\
\text { SW }\end{array}$ & $\begin{array}{l}19 \\
42 \\
32 \\
41\end{array}$ & $\begin{array}{l}17 \\
20 \\
24 \\
23\end{array}$ & $\begin{array}{l}89 \\
47,6 \\
75,0 \\
56,2\end{array}$ & $\begin{array}{r}9 \\
17 \\
11 \\
23\end{array}$ \\
\hline & $\mathbf{W}$ & 1300 & NOO & 28 & 12 & 43,0 & 37 \\
\hline & $\begin{array}{l}\mathbf{X} \\
\mathbf{Y}\end{array}$ & $\begin{array}{l}1800 \\
1900\end{array}$ & $\begin{array}{l}\text { o } \\
\text { So }\end{array}$ & $\begin{array}{l}34 \\
32\end{array}$ & $\begin{array}{r}11 \\
8\end{array}$ & $\begin{array}{l}32,4 \\
25,0\end{array}$ & $\begin{array}{l}26 \\
41\end{array}$ \\
\hline \multirow[t]{2}{*}{$\mathbf{F}^{+}$} & Z & $\begin{array}{l}2000 \\
2000\end{array}$ & $\begin{array}{l}\text { NW } \\
\text { S }\end{array}$ & $\begin{array}{l}14 \\
10\end{array}$ & $\begin{array}{l}1 \\
0\end{array}$ & $\begin{array}{l}7,1 \\
0\end{array}$ & $>105$ \\
\hline & . & WOS, & go & 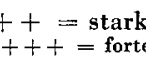 & on Drol & sucht & \\
\hline
\end{tabular}

von X (1800 m, Tab. 10) in 9 (statt 5) Minuten. Für die ersten beiden Fälle orscheint sicher, daß die Königinnen diesen Platz vom Paarungsflug her gut kannten und möglicherweise dort auch begattet wurden. Für die anderen gilt folgende Überlegung : Nicht jede Königin, die man auf einem ihr bekannten Platz aussetzt, wird unverzüglich heimwärts fliegen, sondern die meisten werden zunächst Zeit zur Orientierung brauchen. Deshalb ist die Zahl derer, die den Platz kennen, höher anzunehmen. Wir haben daher die Grenze für die in kurzer Zeit heimfindenden Königinnen nach freiem Ermessen mit 10 Minuten für alle Entfernungen gleich hoch angesetzt in der Annahme, daß die Königinnen für ihre Orientierung erheblich mehr Zeit henötigen werden als für die eigentlichen Rück flüge, deren Unterschiede zudem bei der Kürze der Entfernungen nicht sehr groß sein und deshalb nicht sonderlich ins Gewicht fallen werden.

Lange Rückflüge sind wahrscheinlich zumeist so zu erklären, daß die Königinnen auf dem Platz, auf dem sie ausgesetzt wurden, lange kreisten, bis sie 
zu dem ihnen bekannten Gebiet kamen, von wo aus sie zurückfanden. Sie besagen, daß die Königinnen weit entfernt von dem ihnen bekannten Gebiet ausgesetzt wurden und lassen somit auf eine schlechte Kenntnis der betreffenden Gegend schließen.

Auch die Dauer eines langen Rückfluges wird in erster Linie davon abhängen, in welcher Zeit die Königin bei ihren Suchflügen das ihr vom Hochzeits flug bekannte Gebiet erreicht. Auch hier wird die Dauer des eigentlichen Heimfluges weniger ins Gewicht fallen. Das ihr bekannte Gebiet kann der Paarungsplatz selbst oder der Weg dorthin sein.

Welchen Umkreis auf einem fremden Platz ausgesetzte Königinnen absuchen, ist noch unbekannt. Unbegattete Königinnen, die ihren Orientierungsflug gemacht hatten und die wir in verschiedenen Abständen vom Stock frei ließen, fanden oft schon aus $200 \mathrm{~m}$ Entfernung nicht zu ihrem Stock zurück. Der ihnen vom Orientierungsflug her bekannte Umkreis war also nur sehr gering. Doch hatte man den Eindruck, daß der Bewuchs des Geländes eine Rolle dabei spielt.

Von Königinnen, die nach ihrem Aussetzen nicht zurückkehrten, ist (von Ausnahmen abgesehen) mit Bestimmtheit zu sagen, daß sie den Platz ihrer Freilassung nicht kannten. Sie waren auch von der vom Paarungsflug her bekannten Gegend so weit entfernt, daß sie diese bei ihren Such flügen nicht erreichen konnten. Der Platz der Freisetzung und seine weitere Umgebung ist in diesem Fall als Ort der Paarung und als Teil des Weges zum Paarungsort auszuschließen.

\section{Rückflüge von Drohnensammelplätzen}

Drohnensammelplatz B : $600 \mathrm{~m}$ SW (Höhe $35 \mathrm{~m}$ über dem Standort der Königinnen)

Dieser mäßig von Drohnen besuchte Sammelplatz war den meisten Königinnen gut bekannt (Tab. 3,4). Von ihm kamen die Königinnen am zahlreichsten (zu $89 \%$ ) und schnellsten (im Mittel in 9') zurück, insbesondere im Jahre 1970 (in 4-8'). Einer Königin gelang die Rückkehr (1969) in sogar nur $3^{\prime}$.

Nicht zurück fanden nur 2 von 19 Königinnen. Offenbar hatten sie ihren Hochzeits flug von $20^{\prime}$ und $30^{\prime}$ Dauer in einer ganz anderen Gegend gehalten.

In kurzer Zeit schafften es 14 von 19 Königinnen.

Lange Zeit für ihren Rückflug brauchten nur 3 Königinnen.

10 von allen zurückgekehrten Königinnen kamen von einem zweiten Flug vom $2000 \mathrm{~m}$ von A entfernten Platz Z nicht zurück, kannten jene Gegend also nicht. Der Unterschied zum Erstflug von B aus ist eindeutig. 4 Köni- 
TAB. 4. - Drohnensammelplatz B. Rückfliegeversuche mit 19 Königinnen nach $A(600 \mathrm{~m})$. $\mathbf{C}, \mathbf{E}, \mathbf{Z}=$ Versuche mit den gleichen Königinnen auch von diesen Plätzen aus.

TABL. 4. - Lieu de ressemblement de mâles $B$ : expériences de retour avec 19 reines vers $A(600 \mathrm{~m})$.

$C, E, Z=$ expériences à partir de ces lieux avec les mêmes reines après le $1^{\mathrm{er}}$ vol de retour de $B$ en $A$. (La durée du vol figure alors à côté de la lettre.)

$-=$ reine non rentrée.

. = expérience de 1969. Les autres ont été faites en 1970.

$b=$ reine revenue avec de nouveaux signes de fécondation

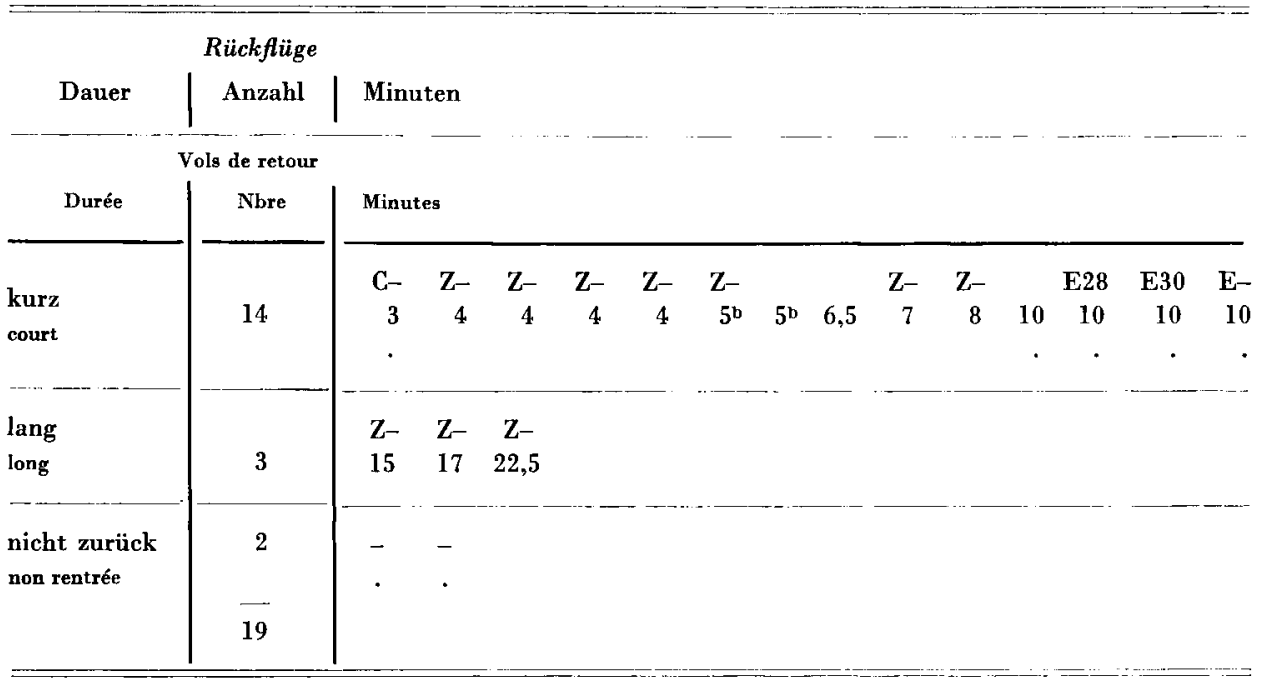

ginnen, die zu einem zweiten Flug von den Drohnensammelplätzen C und E frei gelassen wurden, kannten diese Plätze weniger gut oder nicht.

2 Königinnen ${ }^{b}$, die in $5^{\prime}$ zurückflogen, brachten ein neues Begattungszeichen. Ihre abermalige Paarung muß also schnell erfolgt sein.

Drohnensammelplatz $C: 650 \mathrm{~m} N W$ (Gelände leicht ansteigend bis auf 30 m über den Standort der Königinnen, am stärksten von Drohnen besucht)

Die Rückfliegeversuche von diesem Sammelplatz ergaben ein wesentlich anderes Bild (Tab. 3, 5). Trotz seiner vielen Drohnen war er den Versuchsköniginnen in ihrer Gesamtheit eindeutig schlechter bekannt als der fast ebenso weit südwestlich von A gelegene Sammelplatz B und der $800 \mathrm{~m}$ südöstlich von A gelegene Sammelplatz D. Nur 47,6\% der Königinnen kehrten in durchschnittlich $17^{\prime}$ zurück.

Nur von 3 unter 42 Königinnen, die in kurzer Zeit zurückkehrten, kann man annehmen, daß sie diesen Platz gut kannten.

Viele (22 von 42) kannten diesen Platz und seine Umgebung nicht, und fanden nicht zurück, obwohl 7 von ihnen in mäßig langer Zeit von $\mathrm{D}$ zurückgekehrt waren.

Die übrigen 17 Königinnen fanden nach langer Zeit (11-37') zurück. 


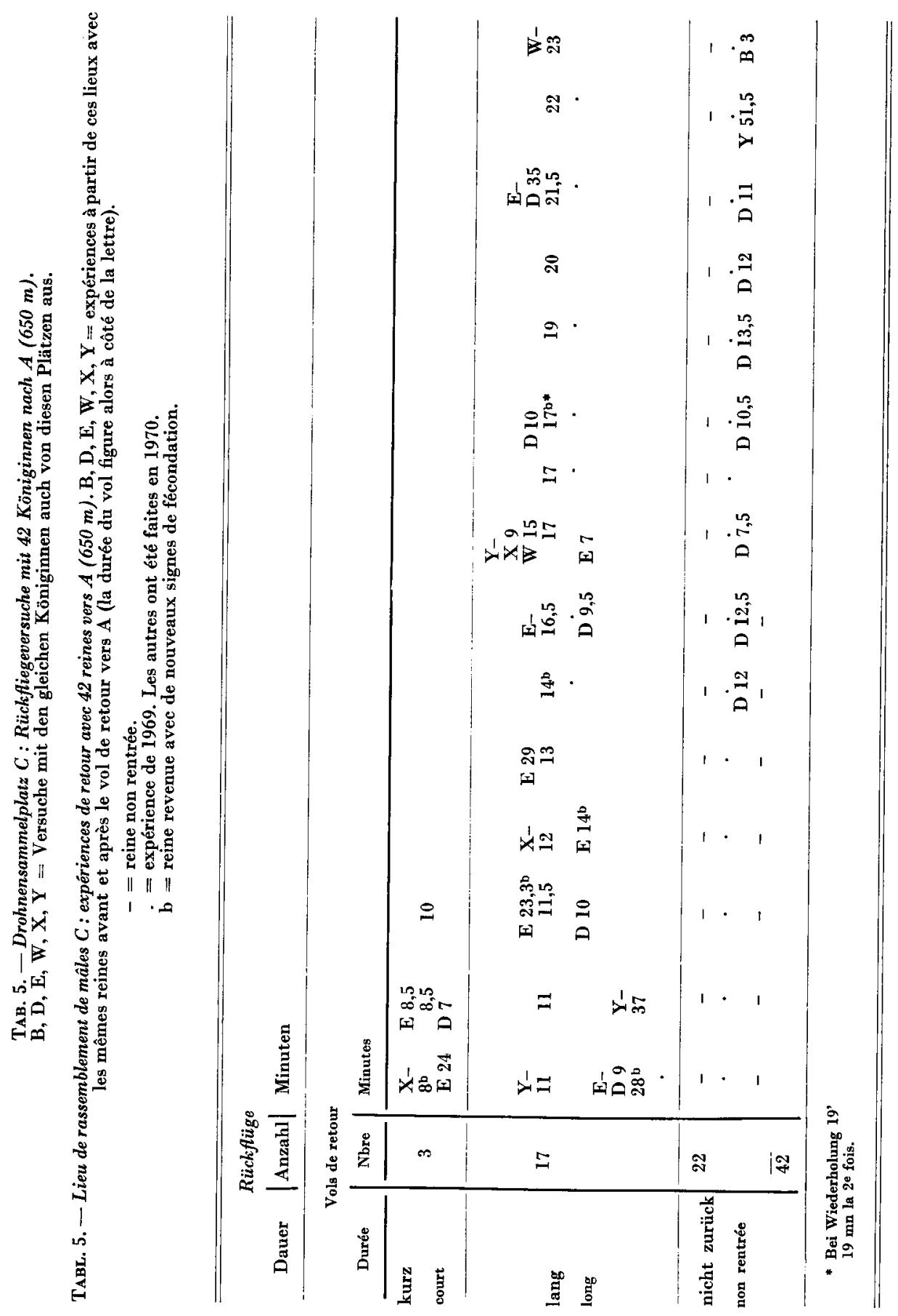


Wahrscheinlich haben sie nicht den Platz selbst, aber doch seine weitere Umgebung gekannt. Eine von ihnen kehrte in $17^{\prime}$ und bei Wiederholung des Fluges in 19' heim, vom Sammelplatz D aber in $10^{\prime}$. Wahrscheinlich hatte sie ihren Hochzeits flug mehr in dessen Nähe gehalten.

Bei Flügen von gleichen Königinnen von verschiedenen Plätzen lagen die Rückkehrzeiten von $\mathrm{C}$ überwiegend über denen von $\mathrm{D}$, im übrigen aber unter denen von $B, E, Y, W$ und $X$. Insbesondere zeigten Königinnen, die wir vorher von $D$ hatten fliegen lassen, daß sie $D$ besser kannten.

4 Königinnen ${ }^{b}$ wurden beim Rück flug abermals begattet.

Drohnensammelplatz D : $800 \mathrm{~m}$ SO, auf Höhenzug, $35 \mathrm{~m}$ über dem Standort der Königinnen

Obwohl der mäßig von Drohnen besuchte Sammelplatz D $150 \mathrm{~m}$ weiter vom Standplatz A der Versuchsköniginnen entfernt lag als $C$, verliefen die Rück flüge von hier bedeutend besser (Tab. 3,6). Die Zahl der nicht zurückgekehrten Königinnen war geringer, die Dauer der Rück flüge kürzer.

Nicht zurück fanden nur 8 von 32, d.h. sie kannten den Sammelplatz mit Sicherheit nicht. Von hier aus gab es die kürzesten Rückflüge $\left(2-10^{\prime}\right.$ bei 13 Königinnen). Lange Zeit brauchten nur 11 von 22.

Die durchschnittliche Rückkehrzeit von $11^{\prime}$ war hier geringer als die von dem näher gelegenen C. Die “ schlechteste " Königin brauchte mehr als 35'. Von $\mathrm{C}$ fand sie etwas schneller und von $\mathrm{E}$ nicht zurück. Aber ihr Paarungs flug hatte nur 4' gedauert. Sie dürfte also mehr in der Nähe ihres Standortes A begattet worden sein.

11 Königinnen wurden auch von $C$ und 9 von $E$ frei gelassen. Sie kamen von dort nur z.T. und nach längerer Zeit wieder. 2 auf $F$ frei gelassene Königinnen fanden von dort nicht zurück. Auch bei den übrigen Mehrfach flügen zeigte sich, daß $D$ besser bekannt war als $C, E$ und $F$.

Eine Königin ${ }^{b}$ wurde auf ihrem $22^{\prime}$ langen Rück flug nochmals begattet.

Drohnensammelplatz $E: 950 \mathrm{~m} S W, 350 \mathrm{~m}$ hinter $B$, über einer Mulde

Der gut von Drohnen besuchte Sammelplatz E war unseren Königinnen in ihrer Gesamtheit mäßig bekannt. Das Versuchsergebnis ähnelt dem von C, obwohl der Platz $300 \mathrm{~m}$ weiter vom Standort der Königinnen liegt (Tab. 3,7).

Nur von 3 unter 41 Königinnen, die in verhältnismäßig kurzer Zeit zurückkehrten, kann man annehmen, daß sie diesen Platz gut kannten. Die in der kürzesten Zeit von $7^{\prime}$ zurückkehrende Königin wurde noch auf 4 anderen Plätzen frei gelassen. 3 dieser 4 Flüge waren von längerer Dauer. Vom 
TAв. 6. - Drohnensammelplatz D. Rückfliegeversuche mit 32 Königinnen nach $A$ (800 m).

$\mathrm{C}, \mathrm{E}, \mathrm{F}=$ Versuche mit den gleichen Königinnen auch von diesen Plätzen aus.

TABL. 6. - Lieu de rassemblement de mâles D. Expériences de retour avec 32 reines vers $A(800 \mathrm{~m})$ $\mathrm{C}, \mathrm{E}, \mathrm{F}=$ expériences à partir de ces lieux avee les mêmes reines avant et après le vol de retour vers $\mathrm{A}$ (la durée du vol figure alors à côté de la lettre).

- = reine non rentrée.

. = expérience de 1969. Les autres ont été faites en 1970.

b = reine revenue avec de nouveaux signes de fécondation.

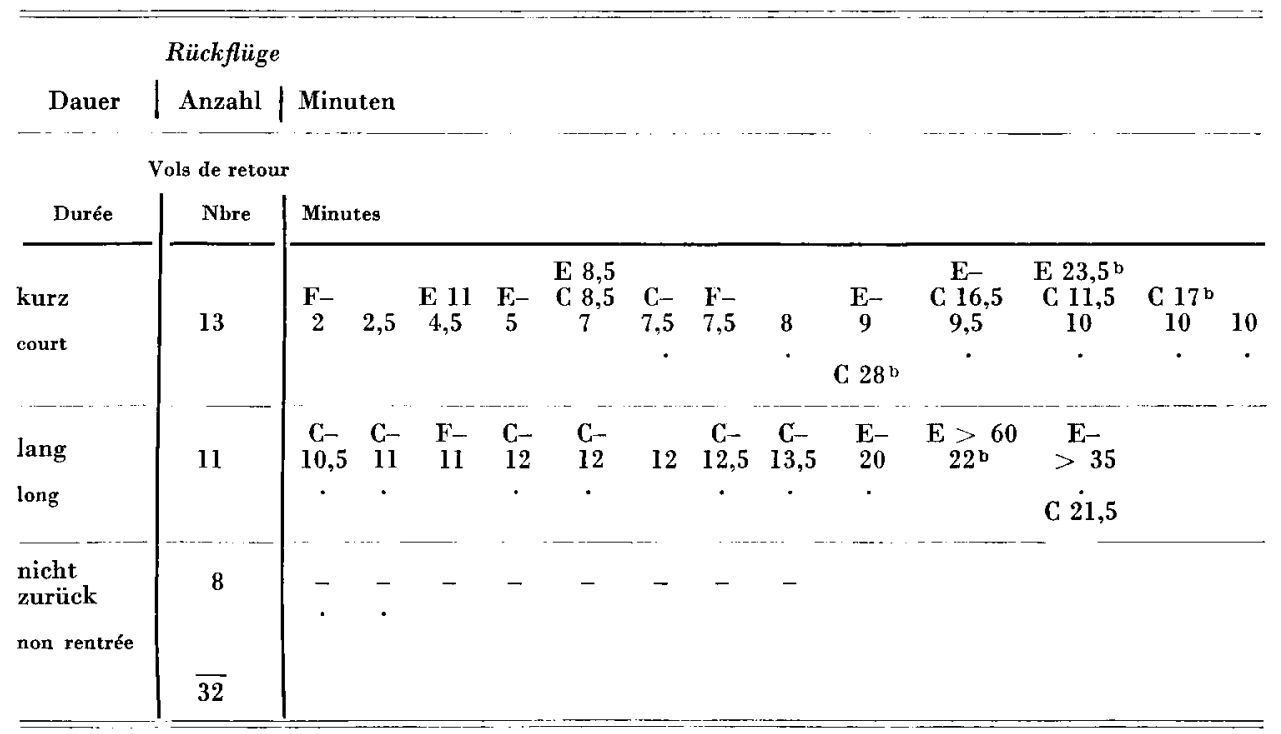

4. Flug (von Y) kam die Königin nicht zurück. Danach kann man annehmen, daß sie sich bei $\mathrm{E}$ paarte.

Viele Königinnen (18 von 41) fanden nicht zurück, d.h. kannten diesen Platz nicht. Wohl hatten 6 von ihnen vorher in 9 Flügen von den Plätzen $B$, C und D zurückgefunden, davon 4 in kurzer Zeit.

Die übrigen 20, die erst nach längerer Zeit (11-60', im Mittel 13') zurückfanden, kannten diesen Platz wahrscheinlich ebenfalls nicht, konnten jedoch eine ihnen bekannte Gegend erreichen.

Auch bei den Mehrfach flügen ergab sich, daß $\mathrm{E}$ besser bekannt war als $\mathrm{X}$, aber meist schlechter als $C$ und $D$.

4 Königinnen ${ }^{\mathrm{b}}$ wurden auf dem Rückflug abermals begattet.

\section{Drohnensammelplatz $F: 2000 \mathrm{~m} \mathrm{NW}$}

Der wahrscheinlich gut von Drohnen besuchte Sammelplatz F (Tab. 3, 8) war so gut wie allen unserer 14 Versuchsköniginnen unbekannt. 


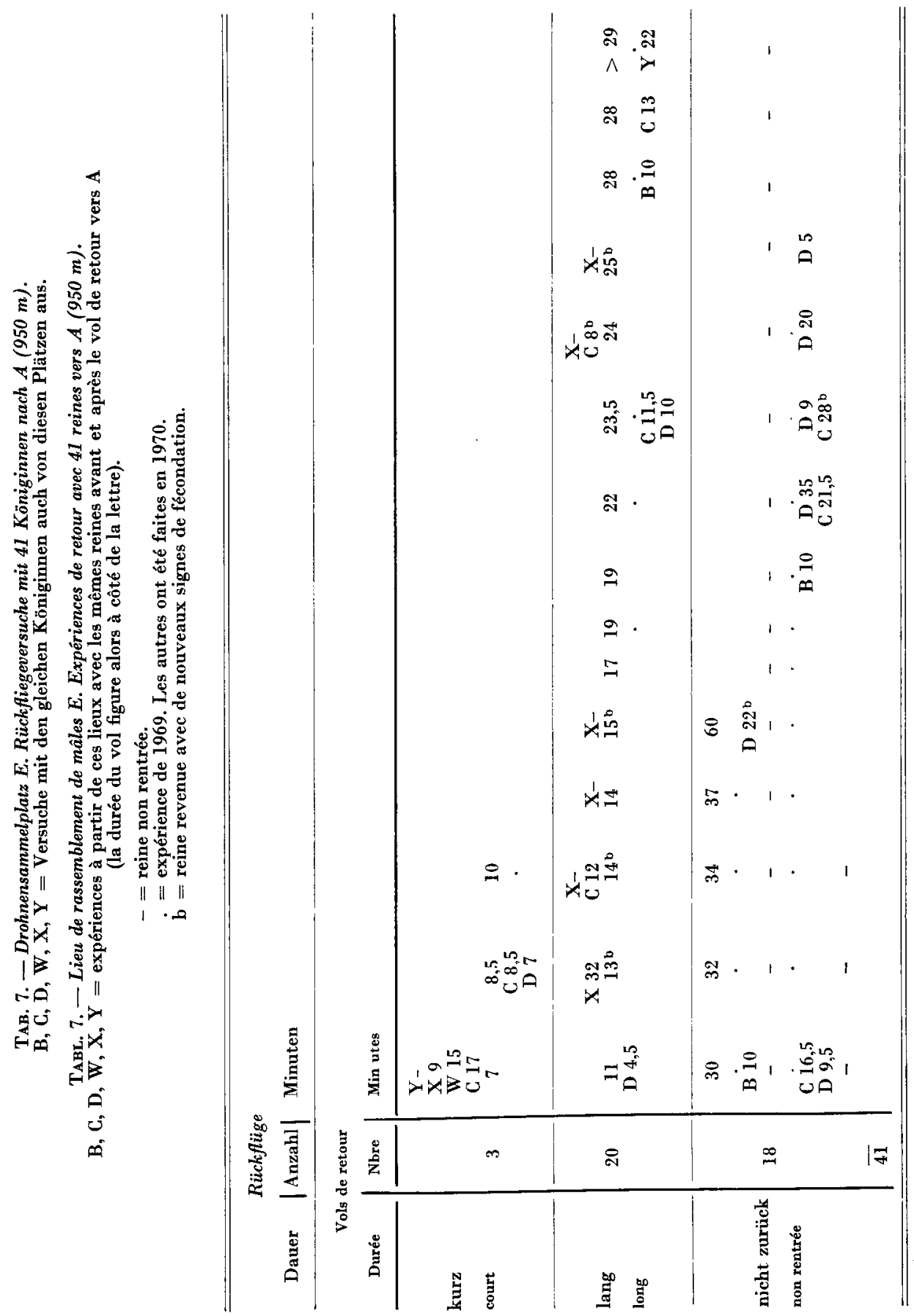


Nicht zurück kehrten 13, die somit diesen Platz bestimmt nicht kannten. Er war zu weit von bekanntem Gebiet entfernt, als daß die Königinnen dieses hätten erreichen und sich heimfinden können. Je 3 dieser Königinnen waren zuvor auf $X$ und $D$ frei gelassen worden und von da aus zurückgekehrt. F lag ihnen zu fern, um sich zurückzufinden.

TAB. 8. - Drohnensammelplatz F. Rüchfliegeversuche mit 14 Königinnen nach $A(2000 \mathrm{~m})$

$\mathrm{D}, \mathrm{X}, \mathrm{Y}=$ Versuche mit den gleichen Königinnen auch von diesen Plätzen aus

TABL. 8. - Lieu de rassemblement de mâles F. Expériences de retour avec 14 reines vers $A$ (2 $000 \mathrm{~m}$ ). $\mathrm{D}, \mathrm{X}, \mathrm{Y}=$ Expériences à partir de ces lieux avec les mêmes reines avant et après le vol de retour vers $\dot{A}$ (la durée du vol figure alors à côté de la lettre).

- = reine non rentrée.

. expérience de 1969. Les autres ont été faites en 1970.

$\mathbf{b}=$ reine revenue avec de nouveaux signes de fécondation.

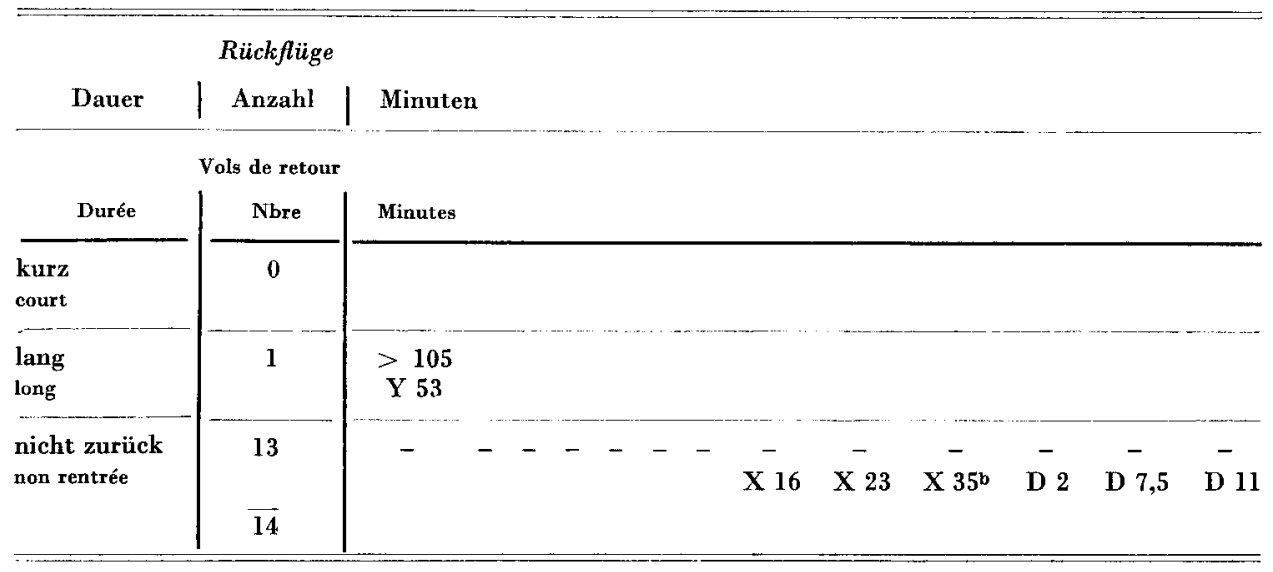

Zurück kam nur 1 Königin. Sie brauchte aber lange, über 105'. Auch von $\mathrm{Y}$ hatte sie sehr lange gebraucht.

Der Drohnensammelplatz F dürfte somit von den Königinnen des Standplatzes A kaum aufgesucht worden sein.

\section{Rückflüge von neutralen Plätzen}

Diese Stellen lagen sämtlich ziemlich weit vom Standplatz der Königinnen. Nur eine Königin fand daher in kurzer Zeit (in $9^{\prime}$ von $\mathrm{X}$ ) zurück.

Neutraler Platz W: $1300 \mathrm{~m}$ NOO

Von W fanden sich die Königinnen (insbesondere 1970) besser zurück als von $X$. W lag ja näher beim Standplatz A (Tab. 3, 9). 
Nicht zurück kamen von insgesamt 28 Königinnen 16. Ihnen war die Gegend also fremd gewesen. Eine davon war vorher von $\mathrm{C}$ frei gelassen worden und nach längerer Zeit (23') von dort wieder erschienen.

Die 12 zurückgekehrten Königinnen hatten sämtlich längere Zeit (37') gebraucht, 5 waren erst nach Abschluß der Beobachtung (nach über 60')

TAв. 9. - Neutraler Platz W. Rüchfliegeversuche mit 28 Königinnen nach $A(1300 \mathrm{~m})$.

$\mathrm{C}, \mathrm{E}, \mathrm{X}, \mathrm{Y}=$ Versuche mit den gleichen Königinnen auch von diesen Plätzen aus.

TABL. 9. - Endroit neutre W. Expériences de retour avec 28 reines vers $A(1300 \mathrm{~m})$.

$\mathrm{C}, \mathrm{E}, \mathrm{X}, \mathrm{Y}=$ expériences à partir de ces lieux avec les mêmes reines avant et après le vol de retour vers $\mathrm{A}$. (la durée du vol figure alors à côté de la lettre).

- = reine non rentrée.

. - expérience de 1969. Les autres ont été faites en 1970.

$\dot{b}=$ reine revenue avec de nouveaux signes de fécondation.

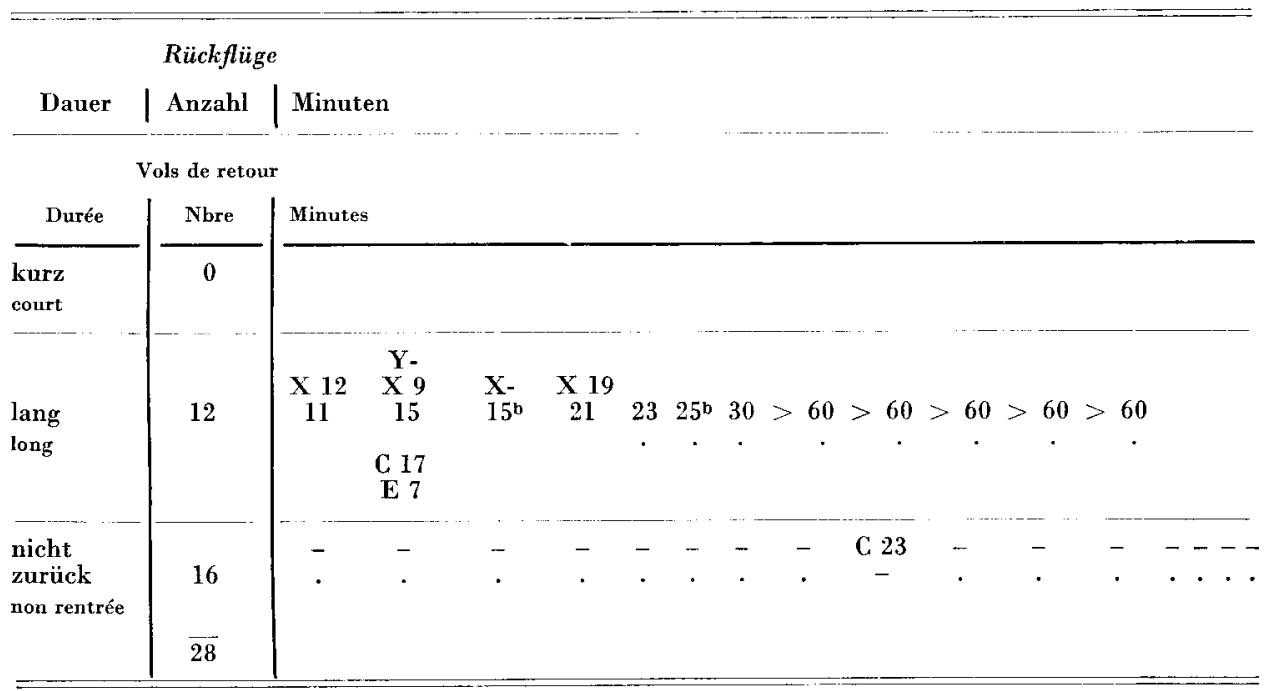

gekommen. Auch ihnen war also der Platz vom Paarungsflug her unbekannt. Jedoch liegt dieser offenbar so nahe bei ihnen bekanntem Gebiet, daß sie es noch erreichen konnten.

Bei 4 Mehrfachflügen wurde teils der Weg von $X$, teils der von $W$ besser gefunden.

2 Königinnen ${ }^{b}$ paarten sich auf dem Rückflug nochmals.

Neutraler Platz X: 1800 m O (500 m östl.von W)

Die Abflugstelle $\mathrm{X}$ und ihre Umgebung war den Versuchsköniginnen schlecht bekannt (Tab. 3, 10).

Nach verhältnismäßig kurzer Zeit $\left(9^{\prime}\right)$ fand nur eine Königin zurück. 
Sie war schon von $\mathrm{E}$ in $7^{\prime}$ zurückgekehrt. Beide Plätze liegen aber ganz entgegengesetzt! Entweder war die Königin beim Hochzeitsflug in entgegengesetzte Gebiete geflogen, oder sie fand sich zufällig schnell zurück. Da es sich um einen Viertflug handelt, und die Königin vorher von der in gleicher Richtung liegenden Abflugstelle $\mathrm{W}$ in $15^{\prime}$ zurückgekehrt war, ist es auch

TAB. 10. - Neutraler Platz X. Rückfliegeversuche mit 34 Königinnen nach A (I $800 \mathrm{~m})$.

$\mathrm{C}, \mathrm{E}, \mathrm{F}, \mathrm{W}, \mathrm{Y}=$ Versuche mit den gleichen Königinnen auch von diesen Plätzen aus.

TaBL. 10. - Endroit neutre $X$. Expériences de retour avec 34 reines vers $A(1800 \mathrm{~m})$.

$\mathrm{C}, \mathrm{E}, \mathrm{F}, \mathrm{W}, \mathrm{Y}=$ expériences à partir de ces lieux avec les mêmes reines avant et après le vol de retour vers $\mathrm{A}$ (la durée du vol figure alors à côté de la lettre).

- = reine non rentrée.

. = expérience de 1969. Les autres ont été faites en 1970.

$b=$ reine revenue avec de nouveaux signes de fécondation.

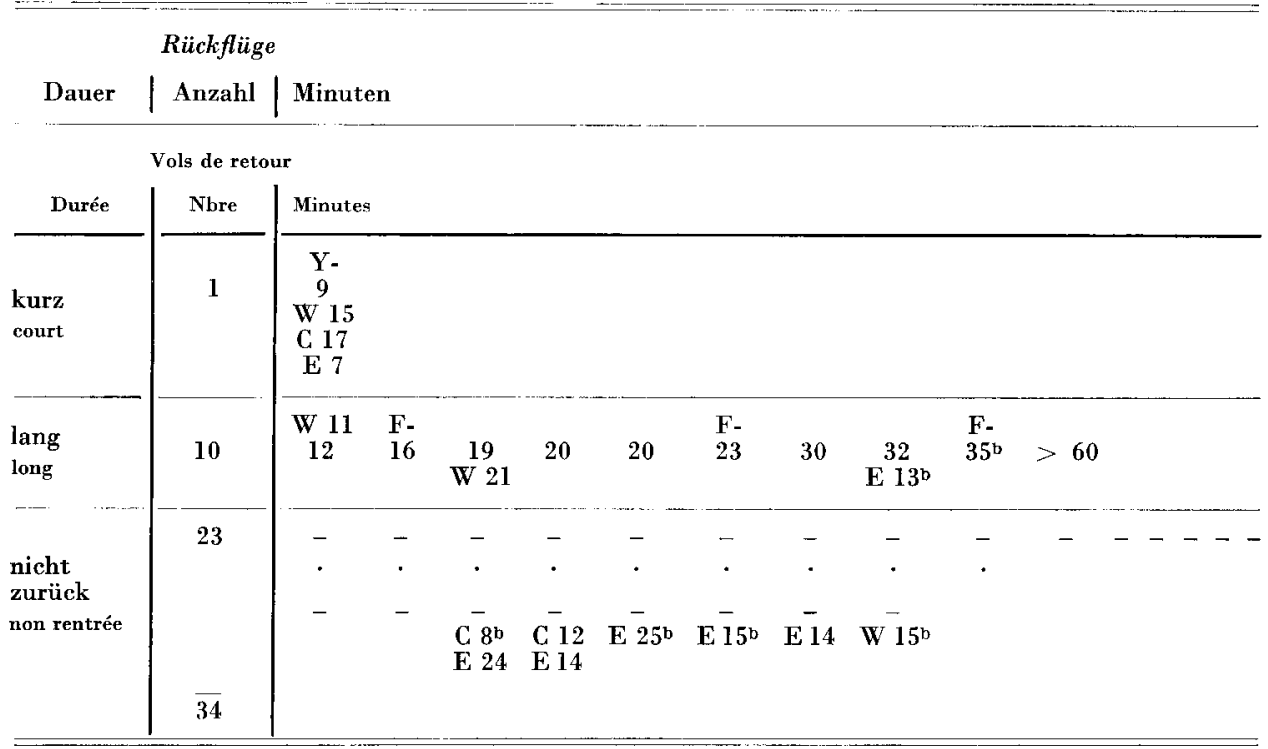

möglich, daß sie den Weg von $\mathrm{X}$ infolge dieser Erfahrung leichter gefunden hat.

Nicht zurück fanden 23 von 34 Königinnen. Sie kannten also die Stelle sicher nicht.

Die übrigen 10 Königinnen brauchten zum Rückflug lange, d.h. 12' bis mehr als 60', im Mittel 26'. Auch daraus ist zu schließen, daß die Stelle selbst den Königinnen nicht von ihrem Hochzeitsflug her bekannt gewesen sein dürfte und sie den Heimweg erst nach einigem Suchen gefunden haben.

Bei den Mehrfach flügen war die Rückkehr von $X$ besser als die von $F$, abe schlechter als die von $C$ und $E$, sowie teils besser, teils schlechter als die von $W$

Eine Königin ${ }^{b}$ wurde auf dem Rückflug wieder begattet. 
Neutraler Platz Y:1900 m SO

Diese Stelle war den Königinnen ähnlich wie X schlecht bekannt (Tab. 3, 11).

TAB. 11. - Neutraler Platz Y. Rüchfliegeversuche mit 32 Königinnen nach $A(1900 \mathrm{~m})$.

C, $\mathbf{E}, \mathbf{F}, \mathbf{W}, \mathbf{X}=$ Versuche mit den gleichen Königinnen auch von diesen Plätzen aus.

TABL. 11. - Endroit neutre Y. Expériences de retour avec 32 reines vers $A(1900 \mathrm{~m})$

$\mathrm{C}, \mathrm{E}, \mathrm{F}, \mathrm{W}, \mathrm{X}=$ expériences à partir de ces lieux avec les mêmes reines avant et après le vol de retour vers $\mathrm{A}$ (la durée du vol figure alors à côté de la lettre).

$-=$ reine non rentrée.

. = expérience de 1969. Les autres ont été faites en 1970.

$\dot{b}=$ reine revenue avec de nouveaux signes de fécondation.

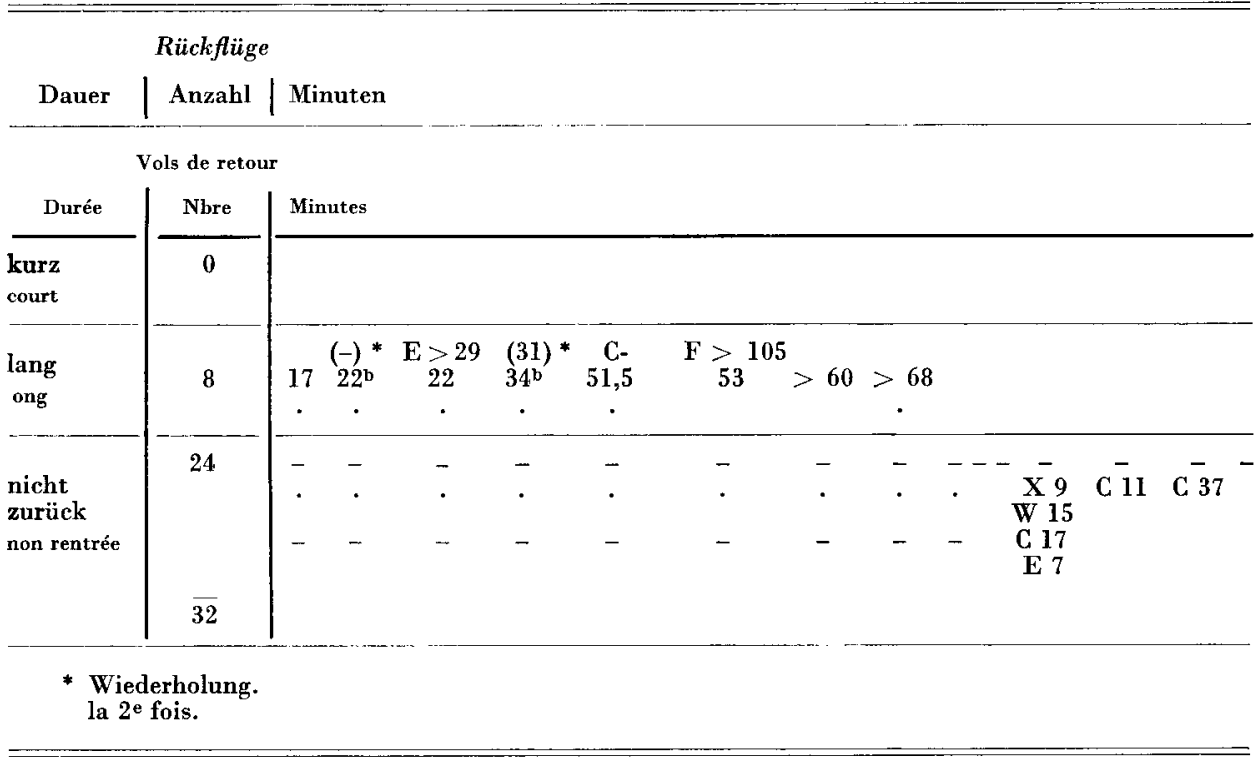

Schnell zurück kehrte von hier aus keine, d.h. keiner Königin war der Platz selbst bekannt.

Nicht zurück fanden 24 von 32 Königinnen, d.h. den meisten war die Gegend völlig unbekannt. Darunter waren 3, die sich vom Sammelplatz C in längerer Zeit zurückgefunden hatten.

Die übrigen 8 Königinnen fanden nach langer Zeit $\left(17^{\prime}\right.$ bis mehr als $68^{\prime}$, im Mittel 41') wieder heim. Auch diesen Königinnen ist die Stelle selbst sicher nicht bekannt gewesen, wohl aber ihre weitere Umgebung. Also ist $\mathbf{Y}$ weit vom Paarungsort der Versuchsköniginnen entfernt. Bei Mehrfach flügen wechselte das Ergebnis. Bei 3 Königinnen war die Rückkehr von hier etwas besser 
als die von $\mathrm{C}, \mathrm{E}$ und $\mathrm{F}$, bei 3 anderen erheblich schlechter als die von $\mathrm{C}, \mathrm{E}$, W und $\mathrm{X}$.

2 Königinnen wurden bei ihren $22^{\prime}$ und $34^{\prime}$ währenden Rückflügen nochmals begattet. Am nächsten Tag ließen wir sie abermals zurück fliegen. Die erste ging dabei verloren. Die zweite kam gleichfalls nach langer Zeit, nämlich nach $31^{\prime}$ zurück. Offenbar hatte sie nicht gelernt, den kürzesten Weg zu wählen.

\section{Neutraler Platz Z : $2000 \mathrm{~m} \mathrm{~S}$}

Der neutrale Platz Z war den Königinnen auch in ihrer weiteren Umbegung vom Hochzeits flug her unbekannt (Tab. 3, 12).

TAв. 12. - Neutraler Platz Z. Rückfliegeversuche mit 10 Königinnen nach $A(2000 \mathrm{~m})$.

$\mathrm{B}=$ Versuche mit den gleichen Königinnen zuvor auch vom Sammelplatz $B$ aus.

TABL. 12. - Endroit neutre $Z$. Expériences de retour avec 10 reines vers $A(2000 \mathrm{~m})$.

$B=$ expériences avec les mêmes reines à partir du lieu de rassemblement $B$.

- = reine non rentrée.

. = expérience de 1969. Les autres ont été faites en 1970.

$b=$ reine revenue avec de nouveaux signes de fécondation.

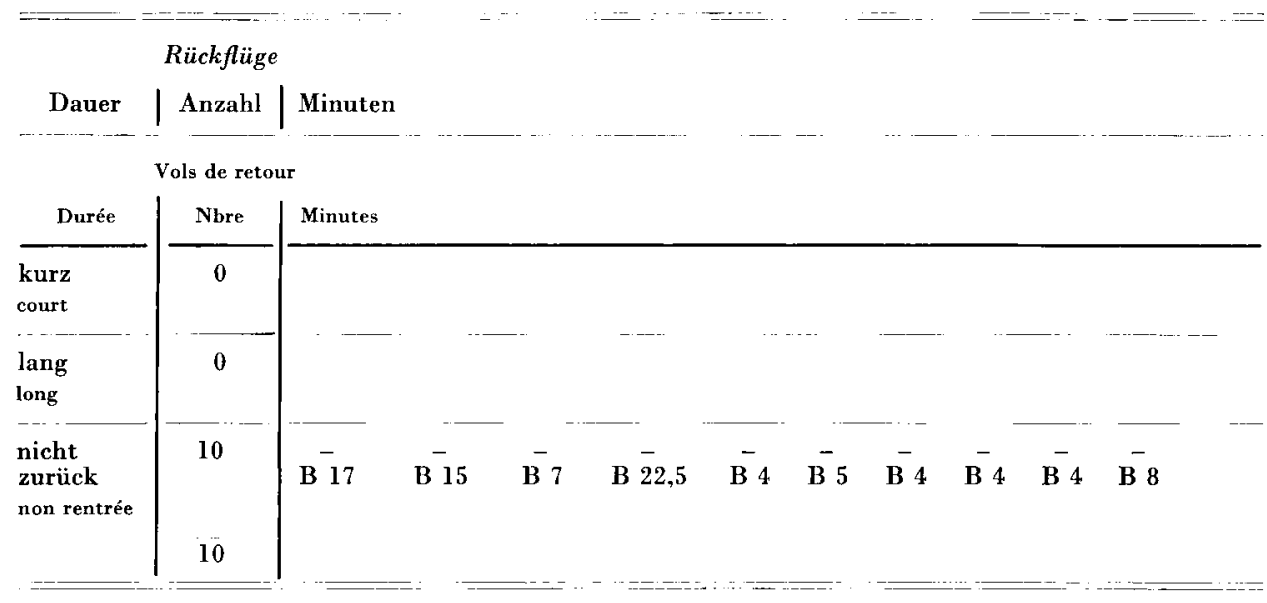

Von 10 Königinnen kehrte, ähnlich wie beim Drohnensammelplatz F, keine zurück. (Bei einem vorhergehenden Versuch hatten sich alle diese Königinnen vom Sammelplatz B zurückgefunden).

\section{GESAMTERGEBNIS}

Aus der Gesamtaufstellung (Tab. 3) wie aus der Kartenskizze (Abb. 1) geht hervor, daß unsere Versuchsköniginnen im großen und ganzen nicht sehr weit geflogen sein können. Denn von den beiden $2000 \mathrm{~m}$ in verschie- 
dener Richtung entfernten Plätzen fand sich nur eine Königin wieder zurück, und das nach sehr langer Zeit. Von den 1800 und $1900 \mathrm{~m}$ entfernten Stellen kamen die Königinnen häufiger wieder, jedoch ebenfalls nach langer und sehr langer Zeit.

Bei rd. $1000 \mathrm{~m}$ (zwischen 950 und $1300 \mathrm{~m}$ ) lag die Grenze, bis zu der sich die meisten Königinnen wieder zurückfanden.

Allgemein kamen die Königinnen umso zahlreicher zurück, je näher sich die Ab flugplätze bei ihrem Standort befanden. Auch die Dauer der Rück flüge war umso kürzer.

Eine Ausnahme bildeten die Rück flüge vom etwa $650 \mathrm{~m}$ nordwestlich gelegenen Drohnensammelplatz C. Während vom. $600 \mathrm{~m}$ entfernten Platz B $89 \%$ und vom 800 m entfernten Platz D $75 \%$ der Königinnen zurückkehrten, waren es hier nur 47,6\%. Und die durchschnittliche Zeit der Rückkehr war mit $17^{\prime}$ ziemlich lang. Von B betrug sie nur $9^{\prime}$ und von D nur 11'.

Offensichtlich waren die Plätze $B$ und $D$ den Königinnen am besten bekannt. Das geht auch aus der Zahl der Königinnen hervor, die zur Rückkehr nur kurze Zeit gebraucht hatten. 14 v. $19=73,6 \%$ waren von $B$ schnell (innerhalb von $10^{\prime}$ ) zurückgekehrt. Von $D$ waren es 13 v. $32=40,6 \%$, von $C$ hingegen nur 3 v. $42=7,1 \%$.

Somit besuchten die Königinnen in der Gesamtheit ihrer Flüge die Gegend südlich ihres Aufstellungsplatzes A mit ihren das kleine Tal begrenzenden Höhen häufiger als die im Norden mit ihrem großen Sammelplatz C am zu einer leichten Anhöhe übergehenden Talschluß.

\section{DISKUSSION}

Zwei Erklärungsmöglichkeiten kommen für die Bevorzugung der südlichen Flugrichtung in Betracht :

1. Horizontmarken können ebenso wie bei den Drohnen (F. und H. Ruttner 1968, 1972) auch bei den Königinnen eine leitende Rolle spielen, die hier von den Höhenzügen ausgegangen sein mögen.

2. Die Königinnen fliegen vermutlich gegen den Wind (Pönıcke 1868, Gary 1963, Butler und Fairey 1964), was auch nach meinen Beobachtungen die geruchliche Anlockung der Drohnen an das Abdomen der Königinnen begünstigt. Und Süden, Südosten und Südwesten sind hier im Sommer bei gutem Paarungswetter die Hauptwindrichtungen!

Im übrigen stimmen unsere Ergebnisse hinsichtlich des Rückkehrvermögens der Königinnen gut mit denen von $G_{A R Y}$ (1971) überein, mit denen von H. und F. Ruttner (1972) hinsichtlich der Flugweite der Königinnen 
jedoch nur annähernd. Bei deren Paarungsversuchen waren die Königinnen weiter ge flogen, im Mittel $2700 \mathrm{~m}$, und im einzelnen bis zu mehr als $5000 \mathrm{~m}$.

Diese verschiedenen Ergebnisse können ihre Ursache in den verschiedenen Versuchsmethoden haben. Denn zweifellos ist der Aussagewert von Rückfliegeversuchen mit Königinnen hinsichtlich der Weite ihres Hochzeitsfluges begrenzt. Aus ihnen ergibt sich lediglich, ob den Königinnen die geprüften Plätze oder deren Umgebung beim Hochzeitsflug bekannt geworden sind, während Paarungsversuche den wahrscheinlichen Paarungsort genauer anzugeben erlauben. Außerdem werden die Feststellungen nach der Rückflugmethode mit zunehmender Entfernung schwieriger. Nimmt doch die Zahl der sich paarenden Königinnen mit wachsender Entfernung stark ab, so $\mathrm{daß}$ eine außerordentlich große Zahl von Königinnen eingesetzt werden müßte, um zu prüfen, wie weit das einigen wenigen Königinnen beim Hochzeitsflug bekannt gewordene Gebiet reicht. So sind extrem weite Paarungsflüge mit Hilfe der Rück flugmethode selbst durch eine große Anzahl von Versuchs flügen praktisch kaum erfaßbar.

$\mathrm{Zu}$ unserem abweichenden Ergebnis kann aber auch beigetragen haben, daß unsere Königinnen ausschließlich auf einem Drohnensammelplatz aufgestellt waren, wo sich zudem die Drohnen der gleichfalls hier stehenden 8 Drohnenvölker befanden. Wenn auch die Königinnen auf diesem Platz nicht oder nur zu einem ganz geringen Teil begattet wurden, so ist doch denkbar, daß sich ihre Flugweite unter dem Einfluß der zahlreichen dort fliegenden Drohnen verkürzte, etwa weil die Drohnen schneller deren Verfolgung aufnehmen konnten. Es war manchmal zu beobachten, daß sich das Fluggeräusch der Drohnen mit dem Ausfliegen der Königinnen auffallend verstärkte und zurückkehrende Königinnen von Drohnen verfolgt wurden. Außerdem schien es, als ob die Königinnen häufiger als sonst schon auf ihrem ersten Ausflug begattet wurden, d.h. daß ihr Orientierungsflug öfter in den Paarungsflug überging.

Die Verschiedenheit der Ergebnisse ist jedoch nicht allein durch die verschiedene Methode erklärbar. Sie kann auch in der andersartigen Umgebung begründet sein. Bei unserem Versuchsgelände handelt es sich um ein Waldgebiet, welches sich als niedriger Höhenzug aus einem ebenen und weniger bewaldeten Gelände hervorhebt. Möglicherweise sind die Drohnensammelplätze und damit auch die Drohnen in diesem Versuchsgebiet verhältnismäßig häufig, in seiner Umgebung jedoch seltener. Es ist somit denkbar, daß sich unsere Königinnen mitten in einem bevorzugt von Drohnen beflogenen Gelände befanden und auf diese Weise von weiten Flügen abgehalten wurden, während im alpinen Versuchsgelände von $H$. und F. RUtrver solche Unterschiede vielleicht nicht bestanden.

Wenn unsere Königinnen ebenso wie die in Rutrner's Versuchen im Mittel $2700 \mathrm{~m}$ geflogen wären, d.h. zu einem großen Teil erheblich weiter als 
nach unseren Versuchen zu urteilen, so müßten viele Paarungen auch in der Ebene außerhalb des bewaldeten Höhenzuges stattgefunden haben. Das aber erscheint in Anbetracht der starken Drohnenpopulation über dem Versuchsgebiet weniger wahrscheinlich. Vor allem hätten sich dann doch entsprechend weitere Rück flüge erzielen lassen müssen.

\section{Findet die Paarung nur auf den Drohnensammelplätzen statt?}

Wie im Abschnitt D festgestellt, paaren sich die Königinnen in der Regel nicht auf einem Drohnensammelplatz, auf dem sie ihren Standort haben. Fliegen sie nun zu anderen Drohnensammelplätzen?

Bei den vorliegenden Rück fliegeversuchen fanden die Königinnen sowohl von den Drohnensammelplätzen wie von den neutralen Ab flugstellen zurück, die keine Drohnensammelplätze waren. Das spricht nicht dafür, daß die Drohnensammelplätze allein die Paarungsplätze sind. Eine Entscheidung dieser Frage ist jedoch wegen der verschiedenen Lage der Plätze nicht möglich. Diese erlaubt keinen schlüssigen Vergleich zwischen dem Rückkehrvermögen der Königinnen von Sammelplätzen und von anderen Stellen.

Am ehesten vergleichbar ist Drohnensammelplatz $\mathrm{E}$ mit dem neutralen Platz W. E ist nicht so weit von $A$ entfernt wie $W$, was erklären kann, weshalb von ihm einige Königinnen mehr zurückkehrten $(56,5 \%)$ als von dem neutralen Platz $(43,0 \%)$. Bleibt zur Beurteilung nur die Dauer der Rück flüge, die von der neutralen Stelle länger war als vom Drohnensammelplatz E. Doch wird man daraus allein nicht auf einen bevorzugten Besuch des Drohnensammelplatzes E vor der neutralen Stelle W schließen können.

An der $2000 \mathrm{~m}$-Grenze liegen der Drohnensammelplatz $F$ und die neutralen Ab flugstellen X, Y und Z. Von Y fanden sich die Königinnen zu $25 \%$, von $X$ zu $32,4 \%$ zurück, allerdings nach langer Zeit, von $F$ und $Z$ so gut wie nicht. Hier war also ein Drohnensammelplatz $(F)$ den Königinnen schlechter bekannt als 2 von 3 neutralen Plätzen. Aber möglicherweise hängt das bessere Rückkehrvermögen von $\mathrm{X}$ und $\mathrm{Y}$ mit der Nähe des den Königinnen gut bekannten Sammelplatzes D zusammen und deren allgemeiner Neigung, in dieser Richtung zu fliegen.

\section{Begattung auf dem Rückflug}

Bei 16 unter $116=13,5 \%$ der zurückkehrenden Königinnen beobachteten wir, daß sie ein neues Begattungszeichen hatten, also beim Rück fluge nochmals begattet worden waren. Bei GARY's Versuchen (1971) war diese Zahl höher : Von 45 Königinnen paarten sich $12=27 \%$ beim Rück flug abermals. 
Diese Rück fluge dauerten im ganzen lange : 5-35 Minuten, im Mittel 17,8 Minuten.

\author{
Es geht daraus hervor, daß die Paarung durch experimentelle Eingriffe \\ nicht unbedingt gestört wird.
}

Eingegangen im Mai 1975.

Reçu pour publication en mai 1975.

\title{
RÉSUMÉ
}

A - Il existe dans la région d'Erlangen 7 lieux de rassemblement de mâles, régulièrement visités tous les ans. Six d'entre eux sont situés dans une région boisée (Fig. 1), le septième sur une hauteur non boisée. La raison pour laquelle les mâles d'abeille recherchent ces endroits précis n'est pas évidente. L'existence de stimuli directionnels à l'horizon, au sens de F. et H. RutTner (1968), est là aussi possible.

Les lieux de rassemblement de la région boisée, qui sont groupés autour de notre ancienne station de fécondation " Hohe Mark ", ont encore été fortement visités après que nous ayons éliminé les 10 colonies à mâles appartenant à notre station de fécondation.

Lors du contrôle des lieux de rassemblement à l'aide de l'expérience du ballon, on s'était aperçu que les premiers mâles étaient présents mi-mai et qu'à la fin du mois d'août des mâles isolés arrivaient encore.

Parfois aucun mâle n'apparaissait aux côtés de la reine expérimentale attachée au ballon. De toute évidence ils n'avaient pas visité le lieu de rassemblement malgré des conditions météorologiques favorables. Ce fut en particulier le cas lorsqu'un temps très chaud suivit une longue période de mauvais temps. Le premier jour, les mâles étaient bien attirés par la reine mais le lendemain ils ne revinrent pas.

B - A fin de savoir si les lieux de rassemblement de mâles sont des lieux d'accouplement, on a tout d'abord examiné si les mâles se laissaient attirer par les reines en d'autres endroits. Nous avons porté entre autres un rucher de 7 colonies à mâles cordovan (cd) en 5 lieux différents. Partout, les mâles furent attirés par les reines expérimentales attachées au ballon, de la môme façon que sur les lieux de rassemblement. Il est vrai que l'un de ces endroits était situé près d'un lieu de rassemblement, cependant des mâles s'y trouvaient déjà avant que l'on ait lâché les colonies expérimentales (cordovan).

L'une des expériences montra que non seulement l'attraction des mâles a lieu peu de temps après l'installation des colonies, mais encore après que les mâles aient volé un certain temps.

$\mathrm{C}$ - On peut obtenir, sur des lieux de rassemblement, aussi bien qu'au-dessus de ruches placées dans des endroits favorables, la copulation de mâles avec des reines mortes dont la chambre de l'aiguillon a été agrandie artificiellement à l'aide d'une fine épingle à insecte de $3 \mathrm{~mm}$ de long (GARY, 1963). Ici, comme là, les mâles sont done bien prêts à l'accouplement.

Il restait encore à examiner si les reines ne s'accouplaient pas aussi naturellement près de leur rucher. Pour cela nous avons réalisé sur l'emplacement d'un rucher, qui n'était pas un lieu de rassemblement de mâles (Fig. 1 Sz), des expériences d'accouplement avec reines cordovan et des mâles. Cette expérience correspondait aux vérifications habituelles faites dans les stations de fécondation. Toutefois grâce à ces expériences d'attraction par ballon, nous avons acquis la conviction que seuls des mâles cordovan survolaient cet endroit.

La plupart des filles (ouvrières) des 12 reines cordovan étaient noires $(56,4 \%)$. Aucune reine ne s'est trouvée être pure, i.e. fécondée exclusivement par des mâles cordovan. Deux reines ont été fécondées uniquement par des mâles noirs, la plupart (10) par un mélange de mâles noirs et de mâles cordovan. 
Par contre, quelques reines (4) installées sur un lieu de rassemblement de mâles ont donné en moyenne $80 \%$ d'ouvrières couleur cuir (cordovan). Bien que les mâles se soient trouvés à $900 \mathrm{~m}$ des reines (Fig. 1, A) on a obtenu dans ce cas un degré de pureté dans l'accouplement plus grand que lorsque les mâles et les reines étaient tous deux au même endroit. Les reines ne s'accouplaient donc pas en majorité sur place ni avec les mâles qui s'y trouvaient.

D - Il s'agissait ensuite de savoir si les reines n'étaient pas plutôt enclines à rester sur place pour s'accoupler lorsque le lieu où elles se trouvaient était un lieu de rassemblement de mâles. A l'aide d'expérience d'accouplement nous avons essayé de répondre à cette question.

En 3 lieux de rassemblement de mâles (Fig. 1 A, C et E), nous avons disposé des reines cordovan pour l'accouplement. Quelques colonies de mâles cordovan vinrent en A. D'après les contrôles le pourcentage de mâles cordovan en l'air était élevé en A, environ $50 \%$, très réduit sur les deux autres lieux, environ 5 et $6 \%$ (Tabl. 1). La descendance des reines expérimentales fut pourtant constituée en chacun des 3 lieux d'environ $30 \%$ d'abeilles cordovan (Tabl. 2), ce qui ne correspondait nullement aux pourcentages de mâles cordovan relevés en l'air. Dans l'ensemble, les reines ne s'étaient donc sûrement pas accouplées sur place, i.e. le lieu de rassemblement de mâles n'exerçait aucun effet stimulant décisif sur la disposition des reines à l'accouplement.

E - Lorsque la majeure partie des reines ne s'accouple pas sur place mais va plus loin, la question se pose de savoir où et jusqu'à quelle distance elles vont.

A cette fin, nous avons réalisé des expériences de retour à partir de lieux de rassemblement (Fig. 1). On a capturé des reines qui rentraient du vol nuptial avec des signes de fécondation et on les a relâchées en un ou plusieurs endroits a fin qu'elles reviennent à leur point de départ. On a ainsi testé 9 endroits (les 5 lieux de rassemblement $B$ à $F$ et les 4 endroits neutres $W$ à $Z$ ) pour savoir s'ils étaient connus des reines, donc considérés comme lieux d'accouplement.

Plus les reines ont été transportées loin, moins bien elles sont rentrées, i.e. elles sont revenues en plus petit nombre et moins rapidement (Tabl. 3 et 4 à 12). Seules quelques reines sont revenues des endroits éloignés de $2 \mathrm{~km}$. Il y a eu du reste des anomalies : le lieu C situé à $650 \mathrm{~m}$ au NE du lieu $A$, bien que fortement visité par des mâles, a été moins bien reconnu des reines du lieu A que de celles des lieux de rassemblement $B$ et $D$ situés respectivement à $650 \mathrm{~m}$ au SSW et à $800 \mathrm{~m}$ au SSE.

Les reines ont eu tendance à voler vers le sud, peut-être le long de 2 chaînes de collines, d'après des points de repère à l'horizon ou contre le vent. La plupart des reines n'a pu voler au-delà de $1000 \mathrm{~m}$ et n'a donc pu aller plus loin pour s'accoupler.

On n'a pas pu décider si l'accouplement avait lieu sur les lieux de rassemblement de mâles ou bien ailleurs.

Il n'était pas rare que les reines se soient accouplées une nouvelle fois lors des vols de retour.

\section{LITERATUR}

Alber M., 1949, Wie weit fliegen Drohnen? Arch.f. Bienenkd. 26, 124-127.

Berlepsch A. von, 1869, Die Biene und ihre Zucht mit beweglichen Waben in Gegenden ohne Spätsommertracht. 2. Aufl. Mannheim.

Bötrcher F. K., 1969, Zum Problem des Hochzeits fluges. 22. Intern. Bienenzüchterkongreß München, 382-384.

Bötтcher F. K., 1971, Wo paaren sich die Bienenköniginnen? 23. Intern. Bienenzüchterkongreß Moskau, 443-445.

Börtcher F. K., Hirschfelder H. und Weiß K., 1966, Die Tätigkeit der Bayerischen Landesanstalt für Bienenzucht, Erlangen im Jahre 1965. Der Imkerfreund 21 (3) 81.

Butler C. G., Fairey M., 1964, Pheromones of the honeybee : Biological studies of the mandibular gland secretion of the queen. J. Apic. Res. 3 (2) 65-76. 
Doonitule G. M., 1892, The two miles theory. Do queens meet drones in the same apiary? Drones congregating. Gleanings in Bee Culture 20 (10) 371-372.

DreHER K., 1957, Welche Folgerungen ergeben sich aus der Mehrfachpaarung für die praktische Zuchtarbeit? Leipziger Bienen-Ztg. 71 (12) 378-381.

Evenius J., 1929, Königinnenzucht-Versuche auf der Greifswalder Oie. Leipziger Bienen-Ztg. 44 (12) 244 .

Gary N. E., 1963, Observations of mating behaviour in the honeybee. J. Apic. Res. 2 (1) 3-13.

GARY N. E., 1971, Observations on flight-experienced queen honeybees following extra-apiary release. J. Apic. Res. 10 (1) 3-9.

Hruschka von, 1868, Versuche über künstliche Befruchtung der Königin. Bienenzeitung (Nördlingen) $24(17 / 18)$ 214-216.

Jean-Prost P., 1958, Résumé des observations sur le vol nuptial des reines d'abeilles. 17. Int. Bienenzüchterkongreß Rom.

KLAtт, G., 1929, Züchtungsmöglichkeiten an der Wasserkante. Arch. f. Bienenkd. 10 (8) 318-321.

KLAtT, G., 1932, Weitere Befruchtungsmöglichkeiten an der Wasserkante! Arch. f. Bienenkd. $13(7 / 8) 243-247$.

Konopacka Z., 1968, Die Hochzeits füge der Königinnen und Drohnen der Honigbiene (Apis mellifera L.). (poln. m. engl. u. russ. Zus.) Pszczelnicze Zeszyty Naukowe 12 (1-2) 1-30.

Koska J., 1955, Drohnen flugweiten. Der Imkerfreund 10 (2) 42.

Levenetz I. P., 1954, Die Flugweite der Drohnen. (russ.) Ptschelovodstwo (8) 36-38. (Ref. Apic. Abstr. 95/1955).

Maul V., 1972, Belegstellen-Prüfungen im Cordovan-Test in : Paarungskontrolle und Selektion bei der Honigbiene. Int. Symposium Lunz am See/Österreich, August 1972.

Meinen G., 1970, Wie sicher ist die Belegstelle Spiekeroog vor fremdrassigem Drohnenzuflug? Nordwestdt. Imkerztg. 22 (5) 128-130.

Oentel E., 1956, Observations on the flight of drone honey bees. Annals Ent. Soc. Amer. 49 (5) 497-500.

Peer, D. F., 1957, Further studies on the mating range of the honey bee, Apis mellifera L. Canadian Entomologist 89 (3) 108.110.

Peer D. F. and Farrar C. L., 1956, The mating range of the honey bee. Jour. Econ. Ent. 49 (2) 254-256.

Pönicke F., 1868, Beherrschung der Befruchtung der Königin. Bienenzeitung (Nördlingen) 24 (17/18) 216-217.

Ruttwer F. u. H., 1965, Untersuchungen über die Flugaktivität und das Paarungsverhalten der Drohnen. 2. Beobachtungen an Drohnensammelplätzen. Z. $f$. Bienenforsch. 8 (1) 1-8.

Ruttwer F. u. H., 1966, 3. Flugweite und Flugrichtung der Drohnen. Z. f. Bienenforsch. 8 (9) 332-354.

Ruttwer F. u. H., 1968, Untersuchungen über die Flugaktivität und das Paarungsverhalten der Drohnen. 4. Zur Fernorientierung und Ortsstetigkeit der Drohnen auf ihren Paarungsflügen. Z. $f$. Bienenforsch. 9, 259-265.

Ruttner H. u. F., 1972, 5. Drohnensammelplätze und Paarungsdistanz. Apidologie 3 (3) 203-232.

ZaNoer E., 1923, 1. Die Flugweite der Drohnen.

2. Die Flugweite der Königin. (In : Bericht über die Tätigkeit der Landesanstalt für Bienenzucht im Jahre 1922.) Erlanger Jahrbuch f. Bienenkd. 1, 145-152.

Zmardicki C., Monse R., 1963, Drone congregation areas. J. Apic. Res. 2 (2) 64-66.

Anschrift des Verfassers : Dr. F. K. BötTcher, D 852 Erlangen, Burgbergstr. 70. 